\title{
Do Teachers' Achievement Goals and Self-efficacy Beliefs Matter for Students' Learning Experiences? Evidence from Two Studies on Perceived Teaching Quality and Emotional Experiences
}

\author{
Martin Daumiller \\ University of Augsburg \\ Raven Rinas \\ University of Augsburg
}

\author{
Stefan Janke \\ University of Mannheim \\ Oliver Dickhäuser \\ University of Mannheim
}

\author{
Julia Hein \\ University of Mannheim \\ Markus Dresel \\ University of Augsburg
}

\begin{abstract}
Although teacher motivation is posited to matter for students' learning experiences, this remains largely uninvestigated, particularly in higher education. In two studies, we analyzed the role of higher education teachers' achievement goals and self-efficacy for students' learning experiences. In Study 1 ( $k=166$ teachers, $n=2,106$ students), we assessed teachers' motivations at the semester start, and students' course-specific perceptions of teaching quality (overall rating, learning) and emotions (joy, boredom) at the semester end. Latent multilevel modeling indicated favorable associations for teachers' self-efficacy, but not for their goals. In Study 2 ( $k=96$ teachers, $n=16,009$ students), we assessed the same constructs and measured students' learning experiences weekly regarding 828 specific course sessions. Additionally, we included teachers' session-specific motivations. Results replicated the effects of self-efficacy on the teacher-level and suggested that performance-approach and performanceavoidance goals primarily matter on the level of specific sessions. This affirms the relevance of teacher motivations and illuminates the importance of their specificity.
\end{abstract}

Keywords: teacher, motivation, goal orientations, self-efficacy, student

(C) 2021, Elsevier. The official citation for this manuscript is: Daumiller, M., Janke, S., Hein, J., Rinas, R., Dickhäuser, O., \& Dresel, M. (2021). Do teachers' achievement goals and self-efficacy beliefs matter for students' learning experiences? Evidence from two studies on perceived teaching quality and emotional experiences. Learning and Instruction. Advanced online publication. https://doi.org/10.1016/j.learninstruc.2021.101458 This paper is not the copy of record and may not exactly replicate the final, authoritative version of the article. The final article will be available, upon publication, via its DOI.

\section{Introduction}

That teachers' motivations matter not only for their own cognition and experiences, but also for their students' learning engagement, is a central assumption behind research into important teacher motivation constructs such as self-efficacy beliefs (Klassen, Tze, Betts, \& Gordon, 2011) and achievement goals (Butler, 2007). In particular, analyzing associations between

Correspondence concerning this article should be addressed to Martin Daumiller, Department of Psychology, University of Augsburg, Universitätsstr. 10, 86159 Augsburg, Germany; Martin.Daumiller@phil.uni-augsburg.de. ORCID: 0000-00030261-6143

The research reported in this article was supported by German Research Foundation Grant DI 929/5-1 to Oliver Dickhäuser and Grant DR 454/8-1 to Markus Dresel.

We have no known conflicts of interest to disclose. teachers' motivations and students' learning experiences is critical for understanding the nature and importance of teacher motivation constructs. Although prior research has established links between primary and secondary school teachers' self-efficacy beliefs and student outcomes, achievement goal-based investigations have primarily documented associations with teachers' attitudes, learning, and stress experiences, while research examining associations with students' learning experiences is lacking. To this end, particularly meaningful aspects entail the product factors of students' perceived teaching quality, namely overall rating and learning, as well as their emotional experiences of joy and boredom. To elaborate, following Marsh (2007), students' overall rating of teaching as well as their learning can be considered central indicators of the quality of teaching, in terms of the outcomes of specific teaching practices on the process level, as 
defined from the perspective of students' subjective experiences (see also Abrami, Apollonia, \& Rosenfield, 2007). Moreover, joy and boredom are emotions that are frequently experienced by students, represent well the theoretical spectrum of possible achievement emotions (as they are differently valanced and activating and root in different control and value appraisals), and have been examined in numerous empirical investigations within classroom settings (aside from emotions experienced in association with examinations), where they have been found to be relevant for problem solving, health, and relationships with others (Frenzel, Goetz, Lüdtke, Pekrun, \& Sutton, 2009; Pekrun, Goetz, Titz, \& Perry, 2002; Pekrun, Goetz, Daniels, Stupinsky $\&$ Perry, 2010). We therefore focus on these four student variables in the present work and investigate how teacher motivations affect them. Furthermore, prior research has mostly focused on teachers in primary or secondary schools, while little is known about the relevance of motivational constructs in higher education teachers - a population who, given its unique and highly important role in society, requires specific research attention (Daumiller, Stupnisky, \& Janke, 2020). In particular, it is not yet clear whether the associations between teachers' motivations for teaching and students' assessments in primary and secondary school contexts can be readily transferred to the higher education context, as systemic differences exist between both teaching contexts. For example, teachers at universities typically have less contact and weaker relationships with their students compared to teachers in schools, while students also differ in their experiences, motivations, and interests (see Beder \& Darkenwald, 1982; Marsh, 2007). ${ }^{1}$ With the present work, we address these research gaps by testing the central, yet largely uninvestigated assumption that teachers' achievement goals and self-efficacy beliefs influence perceived teaching quality and students' emotions within higher education.

\section{Teachers' Achievement Goals and Self-Efficacy Beliefs and Their Relevance for Students' Perceived Teaching Quality and Emotional Experiences}

Against the background of motivation being hypothesized to be composed, in its core, of subjective expectations regarding the desirability as well as the feasibility of potential end states (e.g., Eccles, 1983, 2009), theoretical frameworks have been proposed that focus on value-related and expectancy-related components of motivation. Among them, achievement goals (value-related) and self-efficacy beliefs (expectancy- related) are prominently used in the study of teaching motivations, where it is argued that both constructs should also matter for students.

\subsection{Teachers' Achievement Goals}

The achievement goal approach (Dweck, 1986; Elliot \& Hulleman, 2017; Nicholls, 1984) distinguishes different types of goals that individuals pursue to different degrees, for which different cognitive, behavioral, and affective consequences have been found (Hulleman, Schrager, Bodmann, \& Harackiewitz, 2010). This approach has successfully been used to describe the quality of primary, secondary, and higher education teachers' achievement motivations (Butler, 2007; Daumiller, Dickhäuser, \& Dresel, 2019), and numerous studies have documented associations between teachers' achievement goals and their attitudes, learning, and strain (see Authors, 2020a; Butler \& Shibaz, 2014). In terms of the different types of achievement goals, researchers have distinguished task approach (i.e., striving to conduct professional tasks right), learning approach (i.e., striving to develop own competence), performance approach (i.e., striving to demonstrate superior performance relative to others), performance avoidance (i.e., striving to avoid demonstrating inferior performance relative to others), relational (i.e., striving to create good relationships with students), and work avoidance (i.e., striving to get through the day with little effort) goals (Butler \& Shibaz, 2014; Mascret, Elliot, \& Cury, 2015; see Daumiller, Dickhäuser et al., 2019, for an overview model). ${ }^{2}$ Specifically, prior conceptualizations have focused on appearance (e.g., being perceived as competent) or normative (e.g., surpassing others) aspects of performance-which should be distinguished as they are empirically separable and may entail different effects (Authors, 2020a; see also Daumiller, Dickhäuser et al., 2019; Elliot, 1999, 2005; Hulleman et al., 2010; Lee \& Bong, 2016; Senko \& Dawson, 2017). As teachers are under constant observation by students during teaching, we expect appearance goals to be more strongly tied to actual teaching practice and thus to students' learning experiences than normative goals. Therefore, we exclusively focused on the appearance aspect of performance goals in the present work.

Teachers' achievement goals shape perceptions and interpretations of achievement situations and options for action. As such, they affect teachers' learning (e.g., learning time and strategies), experiences (e.g., emotions), and behaviors (e.g., help-seeking), and beyond 
this, have also been posited to have an influence on students (Authors, 2020b; Butler, 2007; Butler \& Shibaz, 2008). Theoretically, it can be expected that task approach goals should be positively associated with teaching quality and more pleasant student emotions, as task goals are meant to evoke conscientious efforts in fulfilling task requirements (Elliot, Murayama, \& Pekrun, 2011). In the case of teaching, this should directly relate to better preparation, more appropriate and informed didactical decisions, more attention, and better reactions during the teaching itself.

Next to task approach goals, positive effects can also be expected for learning approach goals, as strongly pursuing such goals should elicit the view that teaching contexts provide valuable learning opportunities and make teachers more likely to pursue professional learning opportunities and learn well therein (e.g., Daumiller, Rinas, Olden, \& Dresel, 2020; Hein, Daumiller, Janke, Dresel, \& Dickhäuser, 2019; Nitsche, Dickhäuser, Fasching \& Dresel, 2013). Professional learning can in turn be expected to lead to teachers using more innovative and high-quality teaching methods, which may be suitable for evoking deep learning within students (see also Retelsdorf, Butler, Streblow, \& Schiefele, 2010).

Relatedly, appearance approach goals can also be presumed to have positive associations with teaching quality and students' emotions. In particular, striving to make a good impression should involve better preparation for teaching as well as a more enthusiastic demeanor during teaching (which may be linked to more positive reactions in terms of students' perceptions; Peer \& Babad, 2014).

In contrast, appearance avoidance goals can be expected to be negatively linked to teaching quality and students' emotions. If teachers are worried about their performance and how they are perceived by their students, this might hinder them from fully concentrating on their teaching tasks. Moreover, it may also prompt them to choose "safer" but less-effective teaching methods (e.g., teacher-centered instead of student-centered methods), and simultaneously react negatively to students' questions (e.g., in order to mask knowledge gaps), which could ultimately lead to a negative learning climate in class (see Steuer \& Dresel, 2015).

As relational goals are tied to how strongly teachers seek to achieve and maintain caring and supportive relationships with students, they can be anticipated to have positive associations with students' perceptions of social support, and a positive and motivating classroom climate (Butler, 2012). In consequence, this may facilitate perceptions of higher teaching quality and more pleasant emotions in students.

Finally, work avoidance goals can be posited to lead students to perceive teaching quality to be lower and to experience less pleasant emotions, as teachers striving to get through the day with little effort may be less likely to use innovative didactical approaches, change their lessons despite knowing that they require optimization, or be available to students outside of class.

\subsection{Teachers' Self-efficacy Beliefs}

Self-efficacy beliefs (Bandura, 1977, 1997, 2001) are defined as the subjective beliefs of a person concerning whether they are able to successfully conduct tasks, obligations, and challenges related to their professional role (e.g., didactical tasks, managing discipline problems within the class, etc.; Caprara, Barbaranelli, Steca, \& Malone, 2006; Klassen et al. 2009; Klassen \& Tze, 2014). Self-efficacy beliefs are particularly well-researched regarding primary and secondary school teachers (Klassen \& Tze, 2014), and constitute a topic of rising interest concerning the motivations of teachers in higher education (Daumiller, Bieg, Dickhäuser, \& Dresel, 2019; Fong, Gilmore, Pinder-Grover, \& Hatcher, 2019; Fong, Jendayi, \& Hatcher, 2019; Yin, Han, \& Perron, 2020; Ismayilova \& Klassen, 2019).

Theoretically, teachers' self-efficacy beliefs are presumed to be strongly tied to the decisions they make about choosing, investing effort in, and persisting with teaching activities (Woolfok Hoy, Hoy, \& Davis, 2009). As such, strong self-efficacy beliefs can be expected to lead to a more favorable instructional environment that promotes students' mastery of subject content - as reflected by more student-centered and constructivist teaching approaches (Nie, Tan, Liau, Lau, \& Chua, 2013), or the provision of greater learning support (Holzberger, Philipp, \& Kunter, 2013). This may lead to students' perceiving the teaching to be genuinely engaging, which may spark joy, reduce boredom, and lead to a positive evaluation of the learning activities. In particular, self-efficacy beliefs are likely related to teaching quality and students' emotions in a continuous and dynamic manner (Patterson, Reid, \& Dishion 1992; Sutherland \& Oswald, 2005), i.e., teachers' behaviors and feelings about their teaching efficacy not only influence students (e.g., learning gains, positive reactions), but students (e.g., learning gains, positive reactions) also teachers' self-efficacy beliefs. This may account for particularly robust links between these constructs. 


\subsection{From Teacher Motivations to Students' Learn- ing Experiences: Not so Straightforward?}

In contrast to the alleged importance of the ties between teacher motivation and students' learning experiences, as far as we are aware, only seven studies have considered forms of student-reported criteria in relation to teachers' achievement goals. Taken together, they suggest a rather inconclusive pattern of results and often only considered a small subset of the theoretically relevant types of goals. Furthermore, students' learning experiences were largely neglected, and studies rather focused on criteria such as help-seeking and cheating (Butler \& Shibaz, 2008, 2014), as well as students' achievement motivations (Dresel, Fasching, Steuer, Nitsche, \& Dickhäuser, 2013; Kalyar, Ahmad, \& Kaylar, 2018; Schiefele, 2017; Schiefele \& Schaffner, 2015). The latter resulted in a particularly inconclusive pattern of results: Dresel et al. (2013) found weak links between teacher and student goals that did not match simple theoretical expectations. Schiefele (2017), Schiefele and Schaffner (2015), and Kalyar et al. (2018) considered students' interest and mastery goals: Schiefele and Schaffner (2015) and Schiefele (2017) did not find significant associations regarding these variables for teachers' mastery goals and teachers' selfefficacy beliefs, while Kalyar et al. (2018) did. Only one study took student perceptions of teaching quality into account (Daumiller, Grassinger, Dickhäuser, \& Dresel, 2016): For the two product factors of perceived teaching quality, overall rating and learning, they found positive links with teachers' mastery goals and self-efficacy, as well as negative links with their performance avoidance and work avoidance goals.

Regarding self-efficacy beliefs specifically, accumulating evidence suggests links with cognitive-affective teacher outcomes, classroom processes, teaching quality, and student outcomes (e.g., Lazarides, Buchholz, \& Rubach, 2018; see Zee \& Koomen, 2016 for a review). While associations with the first two groups of constructs are quite clear, associations with the latter group are reported to a lesser extent (Perera \& John, 2020). In particular, there are weaker and less frequent effects within higher school tracks compared to younger students (see Zee \& Koomen, 2016). Considering this line of research, it is worth pointing out that persuasive evidence has been gathered that implies a reciprocal relationship between teachers' self-efficacy beliefs and teaching practices (Holzberger et al., 2013). Finally, for higher education teaching, beyond the study outlined out above (Daumiller et al., 2016), the relevance of self-efficacy beliefs for teaching quality has not often been investigated (for an exception see
Fong, Jendayi, et al., 2019b), and students' emotions have been neglected altogether.

Taken together, these findings indicate that the relevance of teachers' self-efficacy beliefs for students' perceived teaching quality and emotional experiences needs to be investigated in higher education. Furthermore, particularly the links between teachers' achievement goals and student assessments are-while theoretically plausible and postulated as a central assumption behind research on teacher motivation-still not well understood and have only been investigated in a few empirical examinations that did not consistently find the expected relationships. This might reflect that the path from the motivations of teachers to the experiences of students may be rather long. With this, we mean that teachers' general achievement goals for teaching may not straightforwardly translate to students' perceptions and experiences, which could be a function of the stability and specificity of goal pursuit and the influence of further variables.

\subsection{Specificity of Teacher Motivations}

The stability of achievement goal pursuit might be a particularly strong obstacle for finding associations as-especially in teacher motivation researchachievement goals are not often assessed as context- or time-sensitive constructs, but rather in the form of dispositional measures. This largely overlooks the fact that goal pursuit changes over time (Bürger \& Schmitt, 2017; Fryer \& Elliot, 2007) and across different contexts (Bong, 2001, 2004; Sparfeldt et al., 2015). The person-stable fractions of goal pursuit are typically found to be similarly large compared to the variable fractions, also for teachers across multiple months and different classes/sessions being taught (Praetorius et al., 2014; see Authors, 2019).

This means that teachers' goals are likely subject to natural change over the course of the semester, as well as modification regarding the different courses and sessions, with state motivation in class presumably serving as an immediate precondition of teaching behaviors (similar to teachers' emotions; see Frenzel, Goetz, Stephens, \& Jacob, 2009). As achievement goals guide and direct behaviors in achievement situations, the motivations pertaining to a specific teaching situation may be particularly relevant for immediate behaviors and experiences therein. The same can be expected for teachers' self-efficacy beliefs, although the variability of this construct over time and across different contexts has not yet been investigated as systematically as achieve- 
ment goals (cf. Bong, 2002). Therefore, general motivations for teaching at the semester start might not be as relevant for students as teachers' state motivations in class.

Beyond this, further variables (e.g., preparation time, innovativeness of one's courses) and processes (e.g., planning fallacies) might also be directly related to general teaching motivations and absorb or counteract some of their effects over time. For example, teachers with strong learning goals may set out to use particularly innovative methods or teach new topics that they are unfamiliar with, which would make it difficult to achieve high teaching quality and could counteract the positive effects that directly pursuing such goals in class may hold. Similarly, teachers with strong performance avoidance goals for teaching might spend a lot of time preparing their classes in order to avoid things going poorly, which in turn could counteract the detrimental effects that pursuing such goals in class may hold. Considering both general motivations for teaching as well as session-specific motivations may therefore help to better understand how teachers' motivations matter for students' learning experiences.

\section{The Present Work, Research Questions, and Hypotheses}

In the present work, we investigated the central yet largely uninvestigated questions of whether and how teachers' motivations matter for students' learning experiences in higher education. Specifically, we focused on how teachers' achievement goals and self-efficacy beliefs are associated with students' perceptions of teaching quality, including overall rating and learning, and their emotional experiences of joy and boredom.

Based on the theoretical background and the previous empirical findings regarding teachers' goals and self-efficacy beliefs, we hypothesized teachers' task approach goals (H1a), learning approach goals (H1b), performance (appearance) approach goals (H1c), and relational goals (H1e) as well as self-efficacy beliefs (H2) to be positively associated with students' overall rating, learning, and joy, and negatively associated with boredom. Conversely, we expected teachers' performance (appearance) avoidance goals (H1d) and work avoidance goals (H1f) to be negatively associated with students' overall rating, learning, and joy, and positively associated with their boredom.

To test these hypotheses, we conducted two studies with prospective research designs. In order to better understand how teachers' motivations matter and to acknowledge their complex connection with students' experiences, we used study designs that were suitable to provide insights into time- and context-specific effects. Specifically, we assessed student evaluations and teacher motivations at different distances in time by measuring teacher motivations at the semester start and assessing student evaluations at the semester end (Study 1), or within the first third of the semester (Study 2). To further differentiate our findings with regard to situational variation and to provide a finer grained view on time effects, we focused on sessionspecific (i.e., the different sessions within the course) student ratings in Study 2 and did not only consider general motivations for teaching but also session-specific motivations (e.g., session-specific goals alongside general goals at the semester start). In both studies, we considered unfairness and bias variables (students' gender, prior interest, perceived difficulty, reason for participation, course format, teachers' age and gender) that can influence student ratings of teaching and, thus, lead to distorted teaching evaluations if not controlled for (Marsh, 2007; Ting, 2000).

\section{Study 1}

In Study 1, we wanted to confirm that teachers' motivations are predictive of students' perceived teaching quality and emotional experiences. To this end, we used a prospective design with two measurement points. The main goal was to establish associations between teachers' achievement goals and self-efficacy beliefs with students' overall course rating and learning as well their experiences of joy and boredom. In this study, we focused on teachers' general motivations and students' general assessments within one course as a frame of reference.

\subsection{Method}

\subsubsection{Procedure and Sample}

We recruited higher education teachers from Austria and Germany who were willing to participate in a longitudinal study with at least one of their courses. As a prerequisite for participation, the teachers were required to complete a baseline questionnaire assessing their teaching motivations and their students were required to report their learning experiences at the end of the semester. Teachers were invited from both teaching-oriented state universities (e.g., German Universities of Applied Science, "Fachhochschulen") and more research-oriented state universities (German "Universitäten"). Although the study began in 2019 and was 
planned to continue throughout the first half of 2020, the COVID-19 outbreak disrupted these plans. Due to the complicated and hardly comparable teaching situation in the wake of the pandemic, we only used data that was collected prior to February 2020 for the present analyses. In total, this yielded 166 teachers with student assessments (a total of 2,475 student assessments regarding 237 courses). ${ }^{3}$ A subsample of these teachers participated in the study in two semesters, however, the majority only participated once. In order to minimize biases bound to selective repeated measures, we ex ante decided to only include data from the first time a teacher participated, which resulted in a final sample of 2,106 student assessments regarding 202 courses of the 166 teachers.

The participating teachers were on average 38.6 years old $(S D=9.81)$ and included 85 men and 79 women (two teachers did not classify themselves as either male or female), 26 full professors, 73 academic staff members with $\mathrm{PhD}$, and 67 academic staff members without $\mathrm{PhD}$ (which is a typical decomposition for higher education teaching personnel in Austria and Germany). On average, they had $9.8(S D=8.4)$ years of teaching experience and taught in 41 different subjects (mostly from the social sciences and humanities; most frequently: economics, educational science, geography, history, law, philosophy, psychology, and sports science). Students identified themselves as $33 \%$ being male and $60 \%$ being female, and, on average, had been studying at university for 2.3 years $(S D=1.3)$.

\subsubsection{Measures}

Teachers' Achievement Goals. We used the achievement goal scale by Daumiller, Dickhäuser et al. (2019). Following the item stem "In my current teaching activities, ...", task approach (e.g., "I want to fulfill the different requirements very well"; internal consistency: $\omega_{\mathrm{H}}=.90$ ), learning approach (e.g., "my goal is to expand my professional and methodological knowledge as much as possible"; $\omega_{\mathrm{H}}=.93$ ), appearance approach (e.g., "I want to be perceived as competent"; $\omega_{\mathrm{H}}=.91$ ), appearance avoidance (e.g., "I want to avoid being perceived as incompetent"; $\left.\omega_{\mathrm{H}}=.94\right)$, relational (e.g., "one of my main goals is to establish a partnerlike relationship with students"; $\omega_{\mathrm{H}}=.76$ ), and work avoidance goals (e.g., "it is my goal to have the least amount of work as possible"; $\omega_{\mathrm{H}}=.96$ ) were measured with four items each on Likert-type scales ranging from 1 (do not agree at all) to 8 (agree completely).
Teachers' Self-efficacy Beliefs. Self-efficacy beliefs were measured using a university-teaching specific adaptation of the Nie, Lau, and Liau (2012) teaching self-efficacy scale (Daumiller et al., 2016). This scale consists of a total of nine items (e.g., "How well can you provide an alternative explanation or an example when students are confused?") that are to be answered on a Likert-type scale ranging from 1 (absolutely not good) to 8 (exceedingly good). The measure addresses classroom management, instruction, and motivation as three facets of self-efficacy that we analyzed on the overall scale level, like prior research (internal consistency for the overall scale: $\omega_{\mathrm{H}}=.74$ ).

Students' Overall Rating and Learning. We assessed the two product factors of perceived teaching quality using the respective subscales from the SEEQ (Marsh, 1982, 2007). We used the German translation of this scale (Authors, 2020c). We measured students' overall rating of the course with two items ("How does this course compare with other courses you have had?", "How does this instructor compare with other instructors you have had?"; $r=.70$ ) that were to be answered on a Likert-type scale ranging from 1 (very poor) to 5 (very good). Learning was captured with five items (e.g., "I have gained a lot of knowledge in this course"; $\left.\omega_{\mathrm{H}}=.82\right)$ that were to be answered on a Likert-type scale ranging from 1 (do not agree at all) to 5 (agree completely). The learning scale had an extra answer option: not applicable that was subsequently treated as missing data.

Students' Emotions. We assessed students' joy ("joy") and boredom ("boredom") using a five-point Likert-type scale from 1 (not at all) to 5 (very frequently) with single item measures (Goetz, Sticca, Pekrun, Murayama, \& Elliot, 2016) regarding the course at hand (item stem: "How often have you experienced the following in this course?"). ${ }^{4}$

Control Variables. As potential bias and unfairness variables, we assessed students' gender, prior interest in the course topic (single item from Marsh, 2007; scale: $1=$ very little to $5=$ very high), perceived difficulty of the course (single item from Marsh, 2007; scale: $1=$ very easy to $5=$ very hard), and their reason for participation (single item adapted from Marsh, 2007; recoded to $1=$ mandatory, $2=$ mandatory but choice among multiple courses (i.e., students had to participate but selected the course out of different options), 3 =interest), as well as the course format (lecture or seminar) and the teachers' age and gender. 


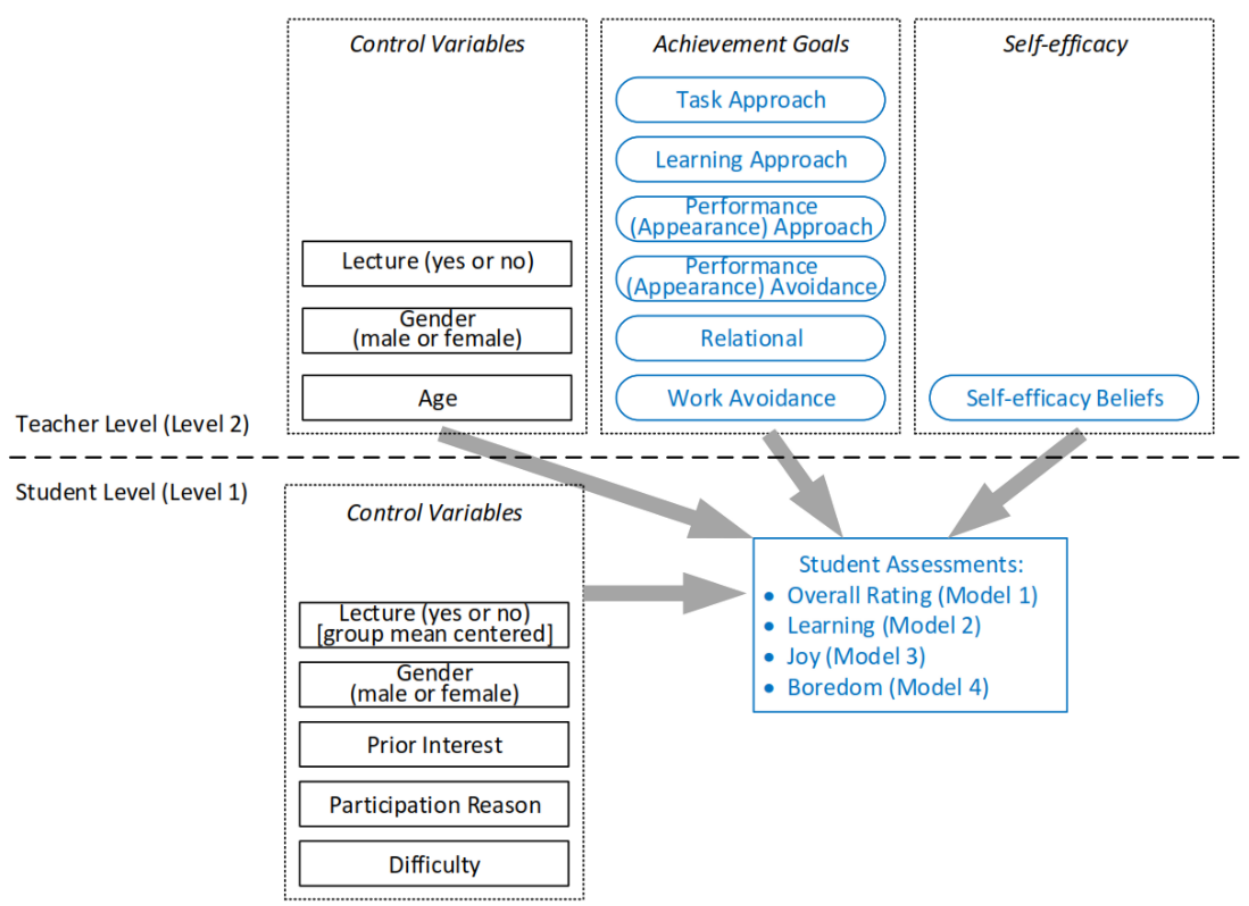

Figure 1. Graphical visualization of the four multilevel models reported in Table 2. Unless otherwise mentioned, all variables were grand-mean centered. Achievement goals and selfefficacy beliefs were estimated as latent variables based on item parcels. Variables of interest for our research questions are highlighted in blue color.

\subsubsection{Analyses}

To investigate our research questions, we conducted latent two-level analyses (Level 1: student assessments, Level 2: teacher assessments; see Figure 1) to adequately reflect the nested student data (Marsh, Lüdtke, Trautwein, \& Morin, 2009). ${ }^{5}$ We modeled course format (which is a course-specific predictor) on the teacher level and also included it group-mean-centered on the student level to reflect that some teachers might participate with multiple courses that may not all have the same course format. On the teacher level, teacher goals and self-efficacy beliefs were modeled as latent variables using item parcels, which is preferable to using items as indicators as it reduces the amount of error in complex model estimations (Little, Rhemtulla, Gibson, \& Schoemann, 2013). Specifically, we used the three facets as parcels for self-efficacy and two parcels for each goal that were created following the item-toconstruct balance method (Little, Cunningham, \& Shahar, 2002). As control variables, we included students' gender, prior interest, reason for participation, and perceived difficulty (Level 1) as well as teachers' age and gender (Level 2). All of these variables were grandmean centered as we wanted to control for the theoretically expected absolute effect of the variables on the course evaluations (Peugh \& Heck, 2016). We estimated one model for each of the four dependent variables (overall evaluation, learning, joy, boredom) in Mplus 8.1 (Muthén \& Muthén, 2017) using the MLR estimator to control for the assumption of multivariate normality not being fulfilled for all variables. There were very few missing values $(\leq 3.3 \%$ for each item on the student level, $\leq 1.8 \%$ for each item on the teacher level) which were dealt with using the FIML estimator and the EM-algorithm for all analyses (Peugh \& Enders, 2004). To evaluate model-fit, we used $\chi^{2}$, SRMR, TLI, RMSEA, and CFI (with CFI, TLI $\geq .95$, SRMR $\leq .08$, and RMSEA $\leq .06$, as cut-off values indicating adequate model fit; $\mathrm{Hu} \&$ Bentler, 1999).

\subsection{Results and Discussion}

Inspection of the descriptive statistics (see Table 1) revealed rather strong task and learning approach goals along with moderate performance goals and self-efficacy beliefs that each contained substantial portions of intraindividual variance. These findings are in line with prior investigations into higher education teachers' achievement goals and self-efficacy and point to this population, on average, having rather adaptive motivations (see Daumiller, Stupnisky et al., 2020). Regarding 
Table 1

Study 1: Descriptive Statistics and Bivariate Correlations

\begin{tabular}{|c|c|c|c|c|c|c|c|c|c|c|c|c|c|c|}
\hline & \multicolumn{3}{|c|}{ Descriptive statistics } & \multicolumn{11}{|c|}{ Bivariate correlations } \\
\hline & $M$ & $S D$ & Skew & 1 & 2 & 3 & 4 & 5 & 6 & 7 & 8 & 9 & 10 & 11 \\
\hline \multicolumn{15}{|l|}{ Students assessments (end-of-course evaluation) } \\
\hline [1] Overall rating & 4.21 & 0.81 & -1.15 & & & & & & & & & & & \\
\hline [2] Learning & 4.10 & 0.71 & -0.87 & .64 & & & & & & & & & & \\
\hline [3] Joy & 3.77 & 0.95 & -0.60 & .60 & .59 & & & & & & & & & \\
\hline [4] Boredom & 2.32 & 1.00 & 0.49 & .55 & -.52 & -.48 & & & & & & & & \\
\hline \multicolumn{15}{|l|}{ Teacher motivations (semester start) } \\
\hline [5] Task approach goals & 7.23 & 0.89 & -1.20 & .13 & .08 & .06 & -.09 & & & & & & & \\
\hline [6] Learning approach goals & 6.91 & 1.12 & -1.38 & .14 & .06 & .10 & -.05 & .51 & & & & & & \\
\hline [7] Performance (appearance) approach goals & 6.17 & 1.36 & -0.84 & .07 & .13 & .10 & -.16 & .31 & .17 & & & & & \\
\hline [8] Performance (appearance) avoidance goals & 6.07 & 1.89 & -0.89 & .02 & .05 & .02 & -.15 & .14 & -.02 & .55 & & & & \\
\hline [9] Relational goals & 5.00 & 1.47 & -0.12 & -.07 & .04 & .02 & .01 & .18 & .27 & .27 & .15 & & & \\
\hline [10] Work avoidance goals & 2.92 & 1.84 & 0.86 & -.01 & .04 & .11 & -.04 & -.45 & -.41 & .14 & .16 & -.02 & & \\
\hline [11] Self-efficacy beliefs & 6.18 & 0.82 & -0.40 & .25 & .22 & .22 & -.22 & .47 & .36 & .21 & -.07 & .30 & -.21 & \\
\hline \multicolumn{15}{|l|}{ Control variables on the student-level } \\
\hline Gender $($ male $=0$, female $=1)$ & .65 & & & -.01 & .02 & -.02 & .09 & -.03 & -.02 & .10 & .06 & .07 & .07 & -.02 \\
\hline Prior interest in topic & 3.68 & 1.14 & -0.60 & .14 & .28 & .25 & -.18 & .03 & .08 & .13 & .06 & .11 & .13 & .11 \\
\hline Participation reason & 1.74 & 0.85 & 0.53 & .20 & .24 & .22 & -.20 & .09 & .00 & .08 & .09 & .06 & .12 & .08 \\
\hline Difficulty & 3.31 & 0.88 & -0.07 & .03 & .04 & -.06 & -.10 & .05 & -.02 & -.03 & -.11 & -.03 & -.11 & .12 \\
\hline \multicolumn{15}{|l|}{ Control variables on course/teacher-level } \\
\hline Age & 38.64 & 9.82 & 0.56 & -.08 & -.08 & -.07 & .12 & -.04 & -.01 & -.13 & -.15 & .09 & -.15 & .04 \\
\hline Gender $($ male $=0$, female $=1)$ & .48 & & & -.04 & -.03 & -.04 & .15 & .12 & .10 & .06 & -.08 & .06 & -.10 & .12 \\
\hline Lecture (yes or no) & .26 & & & -.10 & -.15 & -.12 & .12 & -.05 & -.11 & -.15 & -.02 & .02 & -.12 & -.07 \\
\hline
\end{tabular}

Note. $N=2,106$ student assessments regarding $N=202$ courses taught by $N=166$ teachers. Theoretical range for student assessments, prior interest, and difficulty: 1-5, participation reason: $1-3$, teacher motivations: $1-8$. All correlations with teacher variables are calculated on the teacher level $(|r|>.15: p<.05,|r|>.20: p<.01,|r|>.27: p<.001)$, all others on the student level $(|r|>.04: p<.05,|r|>.06: p<.01,|r|>.08: p<.001)$.

perceived teaching quality and students' emotions, we also found significant differences between the different students, as reflected in the substantial standard deviations. Inspection of the intra-class-correlations of the student ratings (i.e., how strongly the student assessments were similar for the individual teachers) revealed that this variance could be attributed to differences between different teachers (ICC1 $=.17-.31$; corresponding to a medium to large effect size following LeBreton $\&$ Senter, 2008) which sets the ground for the following analyses in which we considered teachers' motivations as explanatory variables for these teacher-specific differences in course assessments.

To this end, our latent multi-level analyses (see Table 2) documented that these teacher-specific proportions of variance in the students' assessments were strongly associated with teachers' self-efficacy beliefs. In particular, teachers' self-efficacy beliefs measured at the beginning of the semester positively predicted students' end-of-course assessments of overall rating, learning, and joy, and were negatively associated with their boredom experienced in the courses of these teachers. This affirms our hypothesis $\mathrm{H} 2$ and is consistent with the theoretical rationale of teachers' selfefficacy beliefs being closely tied to their teaching activities (Woolfok Hoy et al., 2009), as well as empirical findings regarding school teachers (Zee \& Koomen,
2016). Contrary to our expectations, our hypotheses for the achievement goals $(\mathrm{H} 1 \mathrm{a}-\mathrm{f})$ were not supported by the data. We did not find the expected effects for any of the teachers' achievement goals. Surprisingly, for relational goals, we even found an association that contradicted our hypotheses: relational goals were negatively associated with overall course rating.

These results extend the findings of Daumiller et al. (2016), who reported first evidence for associations between (course-specific) teacher motivations and teaching quality but did not consider the temporal stability of such associations (i.e., instead of using a prospective research design, they assessed both constructs simultaneously). In particular, while strongly speaking to the adaptive role of self-efficacy beliefs, our findings may be taken as indication of the effects of achievement goals on students' learning experiences not being as straightforward as often thought. Considering that baseline goals might have been subject to change over time and further variables could have absorbed their effects (e.g., preparation time, amount of innovativeness of one's course), we subsequently extended our investigation by questioning the students earlier and additionally including session-specific teaching motivations. 
Table 2

Study 1: Results of Latent Multi-level Modeling the Associations Between Teachers' Motivations and Perceived Teaching Quality and Students' Emotions

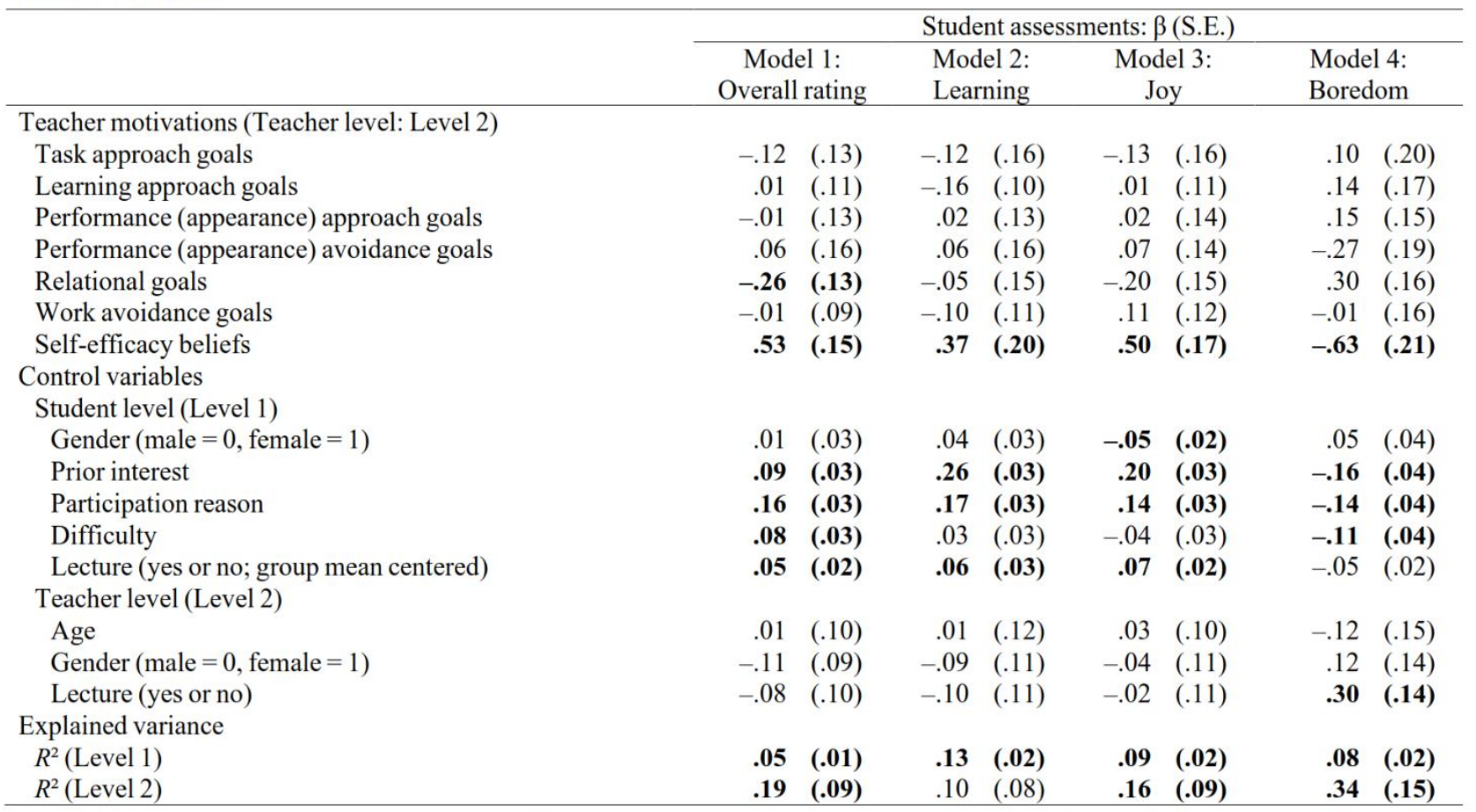

Note. $N=2,106$ student assessments (Level 1) within $N=166$ teachers (Level 2). Statistically significant parameter estimates $(p<.05)$ are boldfaced. Reported are standardized coefficients with their standard errors in brackets. All models yielded a satisfactory fit to the data: $\chi^{2} \leq 152.4, d f=101, \mathrm{CFI} \geq .97, \mathrm{TLI} \geq .95, \mathrm{SRMR}_{\text {Level1 }} \leq .002, \mathrm{SRMR}_{\text {Level } 2} \leq .04, \mathrm{RMSEA} \leq .02$.

\section{Study 2}

In Study 2, we tested the relevance of teaching motivations on students in more detail and elucidated how they matter. To this end, we questioned the students regarding individual sessions within the first third of the semester (instead of end-of-course evaluations) and included teachers' session-specific teaching motivations (along with general teaching motivations at semester start). This reflects our theoretical understanding that goals and self-efficacy beliefs for individual sessions are not solely a function of teachers' general motivations and their change over time, but also a function of the situational affordances and demands (e.g., time pressure or a function of the respective session). Explicit goal setting or updating processes can be expected regarding individual sessions as well as an updating of efficacy expectations concerning the specific tasks involved in the imminent session. Also concerning the content they are directed at, general motivations for teaching and session-specific motivations represent partially different constructs (e.g., general teaching motivations are also directed at teaching activities beyond those occurring in a class, such as lesson planning, following-up on sessions, counselling students, or reading new teaching materials). In our understanding, this means that, compared to generalized motivations that are potentially more prone to planning fallacies, session-specific motivations should be particularly likely to influence teaching within the respective session and, as a result, impact students' learning experiences.

\subsection{Method}

\subsubsection{Procedure and Sample}

We recruited higher education teachers from two German research-oriented state universities who answered a questionnaire about their general motivations for teaching before the semester started. Subsequently, the participating teachers filled out a short questionnaire immediately before each session started for the first five sessions of courses taught (teachers were encouraged to participate using multiple courses). Their students additionally evaluated each of these sessions using end-of-session questionnaires. Altogether, 96 university teachers participated with 182 courses and a total of 828 assessed sessions. Each session was evaluated by an average of $19.3(S D=17.5)$ students, result- 
ing in a total of 16,009 student assessments. The participating teachers (48 men, 48 women; average age: 40.6, $S D=10.4$, years; 39 academic staff members without $\mathrm{PhD} ; 54$ academic staff members with $\mathrm{PhD}$, thereof 3 full professors) taught 37 different subjects mostly within the social sciences and humanities (most frequently: economics, educational science, geography, law, musical education, philosophy, psychology, and sports science). Similar to Study 1, students were $28 \%$ male, $72 \%$ female, and $1 \%$ other, and had on average been studying at the university for 1.9 years $(S D=1.2)$.

\subsubsection{Measures}

We used the same scales as in Study 1 to measure general teaching motivations immediately before the start of the semester (achievement goals: $\omega_{\mathrm{H}}=.83-.94$, self-efficacy beliefs: $\omega_{\mathrm{H}}=.79$ ). In addition, we assessed teachers' current motivations for the specific sessions using a short questionnaire that was strictly derived from the baseline measures. We assessed teachers' goals using single items: For each type of goal, we used the most reliable and face-valid item from the baseline measure and slightly modified them (e.g., for learning approach goals: "In today's session of this course, it is my goal to further develop my own competences as much as possible"). Similarly, self-efficacy beliefs were assessed with three items in total that were derived by selecting the most reliable and face-valid item from the three facets of the baseline measure and referred them to the specific session (e.g., "What do you think: How well can you manage in today's session of this course to keep a few problem students from ruining an entire lesson?"). We present all items in Table S1 in the Supplemental Materials.

Overall rating and learning were assessed with nearly the same scales as in Study 1, with the only differences being that four instead of five items were used to measure student's learning and that both scales were slightly adapted to focus on the individual session instead of the course as a whole (e.g., for overall rating: "How does today's session compare with other courses you have had?"; $r=.75$; ICC2 = .93; learning: "I have gained a lot of knowledge in today's session"; $\omega_{\mathrm{H}}=.83$; ICC2 $=.84$ ). As overall rating consisted of a comparison with other courses/teachers within the students' institution, we standardized it per institution. The ICC2 values reflected good to very good reliability on the session level (assessments of individual students regarding the specific session at hand; Koo \& Li, 2016).

We assessed students' joy and boredom using single item measures by Goetz et al. (2016). At the end of the session, participants reported their emotions experienced during the session ("In today's session I experienced joy/boredom") using a five-point Likert-type scale from 1 (do not agree at all) to 5 (agree completely). Similar to overall rating and learning, the emotions were sufficiently reliable on the session level $(\mathrm{ICC} 2=.54-.84)$.

We assessed the same control variables as in Study 1: students' gender, prior interest (here: regarding the topic of the particular session), their reason for participation, and the perceived difficulty of the session, as well as the course format (lecture or seminar) and the teachers' age and gender.

\subsubsection{Analyses}

Similar to Study 1, we conducted latent multilevel analyses (see Figure 2). We used the shared perspective of the students on perceived teaching quality and emotional experiences during the sessions as outcome variables (one model for each aspect), while using teachers' general motivations for teaching (Level 3) as predictors in three-level models (Level 1: sessions, Level 2: courses, Level 3: teachers). ${ }^{6}$ Like in Study 1, teachers' motivations were modeled as latent constructs based on item parcels. We also used the same control variables as in Study 1: students' gender, prior interest, participation reason, and perceived difficulty (Level 1), course format (Level 2), and teachers' gender and age (Level 3), and additionally included which of the two universities the students/teachers were from as a Level 3 control variable. For our main analyses, we added the session-specific teaching motivations as Level 1 predictors to investigate the specificity of teachers' motivations as predictors of students' learning experiences. We compared the findings of this comprehensive model (specific and general motivations as predictor) with models in which we only included general motivations or only session-specific motivations to confirm that the final results were not distorted and could be well interpreted (partial effects of session-specific motivations after control of baseline motivations). Similar to the control variables, teachers' motivations were grand-mean centered, as we were interested in their absolute instead of their relative effects (Peugh \& Heck, 2016). This reflects that we consider goals and self-efficacy beliefs for individual sessions not merely as deviations centered around a person's general teaching motivation, but as having rather independent means as they tap on different constructs. As such, this centering choice allows for a meaningful investigation of the joint influence of general motivations for teaching and 


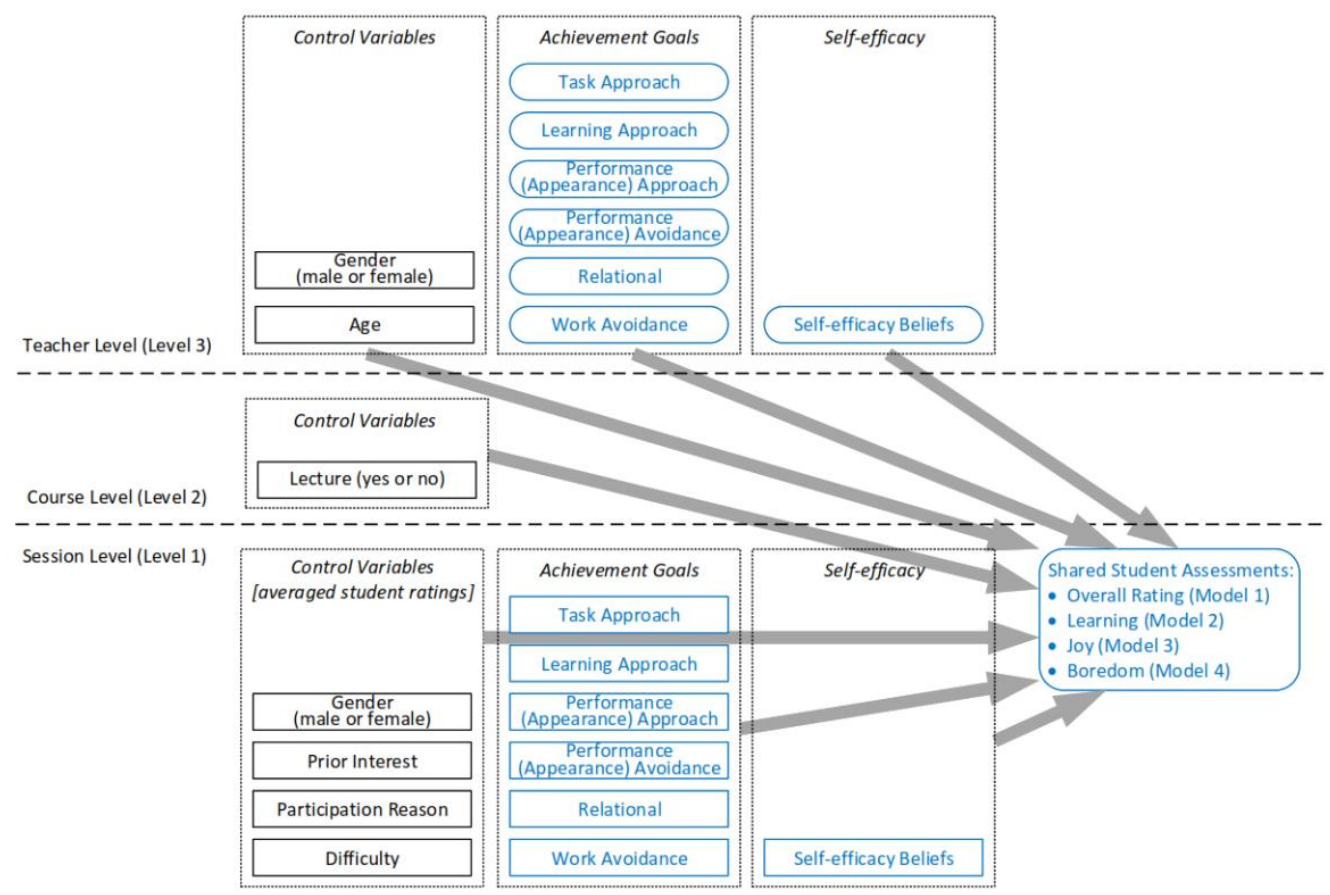

Figure 2. Graphical visualization of the four multilevel models reported in Table 4. All variables were grand-mean centered. Baseline achievement goals and self-efficacy beliefs were estimated as latent variables based on item parcels. Shared perspectives of students on the session level are used as session assessments. Variables of interest for our research questions are highlighted in blue color.

session-specific teaching motivations for perceived teaching quality and students' emotions.

All models were estimated with Mplus 8.1 using MLR as an estimator, and there were very few missing values $(\leq 4.4 \%$ for each item on the student level, $\leq$ $3.1 \%$ for each item on the teacher level) that were dealt with using the FIML estimator and the EM-algorithm for all analyses. We employed the same fit indices and cut-off criteria to determine adequate model fit as in Study 1 .

\subsection{Results and Discussion}

The descriptive statistics (see Table 3 ) for the baseline motivations were very similar to Study 1 . Interestingly, we found the session-specific learning and performance goals to be much weaker than the respective goals from the baseline assessments (which might be taken as indication of teachers being subject to planning fallacies). Together with the medium-to-large correlations (following Cohen, 1988) between session goals and baseline goals (that were in a similar range as re-test or cross-domain correlations often reported for achievement goals, see Daumiller \& Dresel, 2020), this speaks to specific motivations also representing partly different constructs while fundamentally aligning with general motivations. As argued above, one reason for this is likely that general goals for teaching are also directed at factors beyond actual teaching activities in class (e.g., preparing and post-processing lessons, counselling students, etc.) while session-specific motivations may be influenced by other factors such as situational affordances and demands. We observed a comparable correlation coefficient for self-efficacy beliefs that can be interpreted similarly.

We found all motivations to contain substantial portions of variance (which were particularly large for session-specific motivations compared to the general motivations for teaching). Further, the shared student assessments varied significantly between the different sessions. Inspection of their intra-class-correlations revealed that overall rating was rather teacher-specific (proportion of variance that could be attributed to the different teachers: $56 \%$, to the different courses: $23 \%$, remaining on the session-level: $21 \%$ ), while perceived learning, joy, and boredom could be attributed to similarly large parts of the teacher as well as the specific session (teacher: $37-49 \%$ course: $18-19 \%$, session: $34-45 \%)$. Taken together, this shows that large proportions of differences in session ratings are attributable to 
Table 3

Study 2: Descriptive Statistics and Bivariate Correlations

\begin{tabular}{|c|c|c|c|c|c|c|c|c|c|c|c|c|c|c|c|c|c|c|c|c|c|}
\hline & Descrip & tive st & atistics & & & & & & & & Bivar & ariate $\mathrm{cc}$ & correlat & ations & & & & & & & \\
\hline & $M$ & $S D$ & Skew & 1 & 2 & 3 & 4 & 5 & 6 & 7 & 8 & 9 & 10 & 11 & 12 & 13 & 14 & 15 & 16 & 17 & 18 \\
\hline Session evaluations by students & & & & & & & & & & & & & & & & & & & & & \\
\hline [1] Overall rating & 2.88 & 0.58 & -0.45 & & & & & & & & & & & & & & & & & & \\
\hline [2] Learning & 3.83 & 0.33 & -0.41 & .69 & & & & & & & & & & & & & & & & & \\
\hline [3] Joy & 3.75 & 0.41 & -0.29 & .77 & .63 & & & & & & & & & & & & & & & & \\
\hline [4] Boredom & 2.16 & 0.44 & 0.47 & -.71 & -.64 & -.80 & & & & & & & & & & & & & & & \\
\hline Current motivations for specific session & & & & & & & & & & & & & & & & & & & & & \\
\hline [5] Task approach goals & 7.12 & 1.24 & -1.93 & -.04 & -.05 & -.03 & .01 & & & & & & & & & & & & & & \\
\hline [6] Learning approach goals & 5.09 & 2.05 & -0.39 & -.17 & -.10 & -.12 & .13 & .33 & & & & & & & & & & & & & \\
\hline [7] Performance (appearance) approach goals & 4.46 & 2.12 & -0.20 & .17 & .12 & .08 & -.08 & .16 & .23 & & & & & & & & & & & & \\
\hline [8] Performance (appearance) avoidance goals & 4.86 & 2.41 & -0.27 & .01 & -.02 & -.04 & .04 & .16 & .22 & .58 & & & & & & & & & & & \\
\hline [9] Relational goals & 5.22 & 1.82 & -0.50 & .10 & .01 & .07 & -.10 & .20 & .28 & .30 & .22 & & & & & & & & & & \\
\hline [10] Work avoidance goals & 3.04 & 1.98 & 0.76 & .07 & .06 & .06 & -.07 & -.11 & .02 & .17 & .08 & .19 & & & & & & & & & \\
\hline [11] Self-efficacy beliefs & 6.55 & 1.10 & -1.38 & .08 & .08 & .08 & -.07 & .36 & .24 & .20 & .14 & .31 & .05 & & & & & & & & \\
\hline Baseline motivations for teaching & & & & & & & & & & & & & & & & & & & & & \\
\hline [12] Task approach goals & 7.23 & 0.82 & -1.34 & .13 & .01 & .01 & -.08 & .46 & .34 & .14 & .21 & .14 & -.37 & .24 & & & & & & & \\
\hline [13] Learning approach goals & 6.60 & 1.39 & -1.13 & -.05 & .01 & -.05 & .04 & .19 & .56 & .30 & .24 & .20 & -.05 & .17 & .44 & & & & & & \\
\hline [14] Performance (appearance) approach goals & 5.61 & 1.49 & -1.15 & .29 & .22 & .17 & -.19 & .11 & .18 & .70 & .62 & .34 & .16 & .23 & .31 & .33 & & & & & \\
\hline [15] Performance (appearance) avoidance goals & 5.71 & 1.91 & -0.86 & .25 & .12 & .14 & -.18 & .09 & .13 & .63 & .70 & .23 & .09 & .18 & .31 & .27 & .77 & & & & \\
\hline [16] Relational goals & 4.79 & 1.57 & -0.32 & .14 & .16 & .08 & -.09 & .06 & .10 & .25 & .27 & .57 & -.05 & .10 & .29 & .18 & .29 & .25 & & & \\
\hline [17] Work avoidance goals & 2.96 & 1.82 & 0.99 & -.03 & -.05 & .02 & -.04 & -.24 & -.01 & .31 & .25 & .14 & .78 & .01 & -.33 & -.07 & .27 & .22 & -.04 & & \\
\hline [18] Self-efficacy beliefs & 5.96 & 0.88 & -0.47 & .25 & .27 & .22 & -.23 & .17 & .12 & .23 & -.01 & .23 & -.11 & .58 & .19 & .14 & 13 & -.01 & .18 & -10 & \\
\hline Control variables on session-level & & & & & & & & & & & & & & & & & & & & & \\
\hline Gender $($ male $=0$, female $=1)$ & 0.75 & 0.21 & -1.08 & .11 & .10 & .13 & -.16 & -.01 & .02 & -.01 & -.04 & .07 & .07 & .01 & .04 & .11 & .05 & -.04 & .04 & .13 & .10 \\
\hline Prior interest in topic & 3.22 & 0.51 & 0.14 & .46 & .51 & .54 & -.49 & -.06 & -.09 & -.09 & -.11 & -.05 & -.05 & .05 & .12 & .01 & -.09 & -.11 & .10 & -.17 & .11 \\
\hline Participation reason & 1.59 & 0.46 & 0.54 & .05 & .06 & .04 & -.06 & .06 & .14 & -.05 & $-.01-$ & -.13 & -.07 & -.05 & .11 & .10 & -.02 & .03 & -.18 & -.07 & -.02 \\
\hline Difficulty & 2.78 & 0.47 & 0.01 & .01 & .33 & -.03 & -.06 & .01 & .06 & -.09 & -.06 & -.11 & -.13 & .07 & .14 & .07 & -.08 & -.14 & .03 & -19 & .04 \\
\hline Control variables on course-level & & & & & & & & & & & & & & & & & & & & & \\
\hline Lecture (yes or no) & .12 & & & -.18 & -.19 & -.27 & .30 & .10 & .13 & .11 & $.11-$ & -.01 & .05 & .05 & -.01 & .06 & .05 & .09 & .02 & .03 & -.01 \\
\hline Control variables on teacher-level & & & & & & & & & & & & & & & & & & & & & \\
\hline Age & 40.55 & 10.43 & 0.28 & -.02 & .01 & .09 & .05 & .08 & .14 & -.15 & -.23 & .08 & -.20 & .13 & .02 & .02 & -.18 & -.24 & .09 & -.26 & .23 \\
\hline Gender $($ male $=0$, female $=1)$ & .50 & & & .01 & -.14 & -.05 & -.04 & .20 & -.06 & .06 & .07 & -.02 & -.03 & .09 & .11 & .08 & .23 & .24 & -.15 & .03 & -.07 \\
\hline University (University A or University B) & .47 & & & .07 & -.12 & -.03 & -.03 & .11 & -.06 & .21 & .19 & .12 & .23 & .01 & -.20 & -.12 & .16 & .16 & -.10 & .20 & -.11 \\
\hline
\end{tabular}

differences between different teachers, while also large portions of variance remain that cannot be attributed to the different courses or general attributes of the teachers, but possibly to session-specific motivations of the teachers as we investigated next.

To this end, we conducted latent three-level modeling. In a first step, analogous to Study 1, we included the general teaching motivations on Level 3 (see Table S2, Supplemental Material). For this, we found similar, large effects for self-efficacy beliefs that positively predicted students' overall rating, perceived learning, and joy, and negatively predicted boredom. In addition, learning was positively predicted by performance approach goals and negatively by work avoidance goals. Surprisingly, learning was also negatively predicted by teachers' task goals and overall rating was negatively predicted by learning goals.

This last effect did not remain when including teachers' session-specific motivations in the model, while all other Level 3 effects were robust (Table 4). In these main analyses of the present study, on the session level we found the expected adaptive associations for performance approach goals (being positively related to overall rating and learning and negatively related to boredom) and the expected maladaptive associations for performance avoidance goals (being negatively related to overall rating, learning, and joy, and positively related to boredom). Besides this, task goals positively predicted students' experiences of joy. Furthermore, we found four unexpected effects: Relational goals were negatively associated with perceived learning and boredom, and learning goals were negatively associated with overall rating and positively associated with boredom.

To confirm the robustness of these effects of session-specific motivations, we also estimated the previous models without the general teaching motivations on Level 3 but only the session motivations on Level 1 . The results (see Table S3) confirmed that all effects except the positive link between task approach goals and joy (and the negative link between performance avoidance goals and overall rating) remained when excluding the baseline motivations. Furthermore, self-efficacy beliefs also emerged as positive predictors of overall rating, learning, and joy. This speaks to the strong effect of general self-efficacy beliefs that also shows on the session level, while achievement goal effects are robustly (and in particular, not substantially distorted due to partial effects) found on the session level but not on the teacher level. ${ }^{7}$ 
Table 4

Study 2: Results of Latent Multi-level Modeling the Associations Between Teachers' Motivations and Perceived Teaching Quality and Students' Emotions

\begin{tabular}{|c|c|c|c|c|}
\hline & \multicolumn{4}{|c|}{ Student assessments: $\beta$ (S.E.) } \\
\hline & $\begin{array}{c}\text { Model 1: } \\
\text { Overall rating }\end{array}$ & $\begin{array}{l}\text { Model 2: } \\
\text { Learning }\end{array}$ & $\begin{array}{c}\text { Model 3: } \\
\text { Joy }\end{array}$ & $\begin{array}{l}\text { Model 4: } \\
\text { Boredom }\end{array}$ \\
\hline \multicolumn{5}{|l|}{ Current motivations for specific session (Level 1) } \\
\hline Task approach goals & $.02(.04)$ & $.01(.04)$ & $.07(.04)$ & $-.07(.04)$ \\
\hline Learning approach goals & $-.13(.06)$ & $.02(.05)$ & $-.03(.06)$ & $.13(.06)$ \\
\hline Performance (appearance) approach goals & $.13(.07)$ & $.10(.06)$ & $.06(.06)$ & $-.12(.06)$ \\
\hline Performance (appearance) avoidance goals & $-.11(.06)$ & $-.10(.04)$ & $-.16(.06)$ & $.15(.05)$ \\
\hline Relational goals & $.04(.06)$ & $-.12(.05)$ & $-.01(.05)$ & $-.14(.05)$ \\
\hline Work avoidance goals & $-.01(.06)$ & $.06(.06)$ & $-.04(.06)$ & $.04(.06)$ \\
\hline Self-efficacy beliefs & $.06(.05)$ & $.08(.06)$ & $.07(.06)$ & $-.02(.06)$ \\
\hline \multicolumn{5}{|l|}{ Baseline motivations for teaching (Level 3) } \\
\hline Task approach goals & $-.09(.15)$ & $-.41(.17)$ & $-.25(.15)$ & $.10(.17)$ \\
\hline Learning approach goals & $-.23(.12)$ & $-.09(.13)$ & $-.15(.12)$ & $.17(.14)$ \\
\hline Performance (appearance) approach goals & $.25(.24)$ & $.48(.24)$ & $.08(.29)$ & $.03(.32)$ \\
\hline Performance (appearance) avoidance goals & $.31(.22)$ & $.11(.22)$ & $.47(.26)$ & $-.50(.29)$ \\
\hline Relational goals & $-.06(.13)$ & $.06(.16)$ & $-.06(.16)$ & $.18(.17)$ \\
\hline Work avoidance goals & $-.14(.13)$ & $-.25(.15)$ & $.07(.14)$ & $-.04(.17)$ \\
\hline Self-efficacy beliefs & $.30(.13)$ & $.27(.14)$ & $.29(.13)$ & $-.32(.15)$ \\
\hline \multicolumn{5}{|l|}{ Control variables } \\
\hline \multicolumn{5}{|l|}{ Session/student characteristics (Level 1) } \\
\hline Gender & $.02(.06)$ & $-.01(.04)$ & $.03(.04)$ & $-.07(.05)$ \\
\hline Prior interest & $.61(.04)$ & $.46(.04)$ & $.63(.04)$ & $-.60(.04)$ \\
\hline Participation reason & $.03(.07)$ & $-.02(.04)$ & $.03(.05)$ & $-.03(.05)$ \\
\hline Difficulty & $.06(.05)$ & $.40(.04)$ & $-.10(.05)$ & $.01(.04)$ \\
\hline \multicolumn{5}{|l|}{ Course characteristics (Level 2) } \\
\hline Lecture (yes or no) & $-.28(.08)$ & $-.30(.11)$ & $-.43(.08)$ & $.48(.08)$ \\
\hline \multicolumn{5}{|l|}{ Teacher characteristics (Level 3) } \\
\hline Age & $-.11(.12)$ & $-.28(.12)$ & $.06(.13)$ & $.15(.14)$ \\
\hline Gender & $-.06(.11)$ & $-.16(.11)$ & $.01(.13)$ & $-.08(.14)$ \\
\hline \multicolumn{5}{|l|}{ Explained variance } \\
\hline$R^{2}$ Level 1 & $.44(.05)$ & $.52(.04)$ & $.42(.05)$ & $.44(.04)$ \\
\hline$R^{2}$ Level 2 & $.08(.05)$ & $.09(.07)$ & $.19(.07)$ & $.23(.08)$ \\
\hline$R^{2}$ Level 3 & $.29(.11)$ & $.42(.12)$ & $.34(.11)$ & $.32(.13)$ \\
\hline
\end{tabular}

Note. $N=828$ assessed sessions (Level 1) within $N=182$ courses (Level 2) taught by $N=96$ teachers (Level 3). Reported are standardized coefficients with their standard errors in brackets. The dependent variables are the between part of student' session assessments (based on a total of $N=16,009$ student assessments). Statistically significant parameter estimates $(p<.05)$ are boldfaced. All models yielded a satisfactory fit to the data: $\chi^{2} \leq 122.0, d f=94$, $\mathrm{CFI} \geq .97, \mathrm{TLI} \geq .95, \mathrm{SRMR}_{\text {Level1 }} \leq .01, \mathrm{SRMR}_{\text {Level2 }} \leq .04, \mathrm{SRMR}_{\text {Level3 }} \leq .06, \mathrm{RMSEA} \leq .02$.

\section{General Discussion}

That teacher motivations also matter for students is a central, yet largely uninvestigated assumption, particularly regarding higher education teaching. In the present work, we addressed this tenet of teacher motivation research in two studies. Using prospective research designs, we delivered first findings concerning the association between teachers' motivations and students' perceived teaching quality and emotional experiences
(Study 1), and supplemented these using a more finegrained approach in which we considered situationspecific alongside general teaching motivations at the semester start (Study 2). Strengths of our work include the explicit use of students' assessments, the consideration of the multilevel data-structure, the analyses being conducted on the latent level, as well as the incorporation of bias and unfairness variables in the statistical models. Taken together, robust findings of both studies support the notion that teachers' general self- 
efficacy beliefs can serve as a (dispositional) resource for the facilitation of positively perceived teaching. Session-specific self-efficacy beliefs were less important, potentially indicating that the impact of this aspect of teachers' motivations on students' learning experiences is largely bound to stable parts of the construct. We observed the opposite for achievement goals, that mostly evoked effects on the situational (session-specific) level, and were not as relevant on the more general level. Moreover, we found that sessionspecific performance approach goals were most strongly associated with a positive learning experience by the students during a given session, whereas performance avoidance goals exhibited negative effects. All other goals were less conclusively related to students' perceived teaching quality and emotional experiences. An especially interesting result was that we did not find the presumed, favorable links for task or learning goals (instead, they exhibited negative associations with students' experiences) in our multilevel analyses, which contributes to a more nuanced picture of how teacher motivations matter.

\subsection{Implications}

Besides the central result that teachers' motivations are indeed associated with students' perceived teaching quality and emotional experiences, we found that this association is not trivial and that the specificity of motivations needs to be accounted for. This implies that if researchers were to only use general measures to investigate teaching motivation, they might conclude that only teachers' self-efficacy beliefs matter in predicting students' learning experiences. Theoretically, such a conclusion aligns well with dispositional self-efficacy being a strong resource for coping with situational demands (see Woolfok Hoy et al., 2009). Conversely, if researchers used only situational measures, they might conclude that teachers' achievement goals are a particularly important aspect of their motivations regarding students' learning experiences. This likely reflects that personal goals are structured as hierarchical systems ranging from very general life aspirations to very specific situated achievement goals (see also Austin \& Vancouver, 1996; Janke \& Dickhäuser, 2018, 2019). When humans think about more abstract values or goals, they likely do not construe the affordances and demands of specific situations (Eyal, Sagristano, Trope, Liberman, \& Chaiken, 2009). However, the teaching practice itself is strongly bound to situational ramifications such as time constraints, students' ability levels, and momentary workload, while excluding further aspects subsumed by general teaching motivations, such as planning and following-up on sessions or counselling students outside of class. Thus, goals may be more predictive if individuals construe them in a situated manner, as was the case when we asked teachers about their goals for the immediate sessions. This might also explain why certain types of goals that are usually considered to be very desirable in the teacher population, such as learning goals, were weaker when the teachers took the situational demands into account. More specifically, we interpret this finding in the light of them making fewer planning fallacies when considering whether they will be able to learn in a certain session compared to when they take a more abstract view on their course or their teaching practices in general.

A strength of our approach to achievement motivation is that we took a differentiated view on achievement goals by including relational and work avoidance goals while simultaneously disentangling task and learning goals and focusing performance goals exclusively on the appearance aspect to gather a clearer interpretation of the findings (see Hulleman et al., 2010). This allows us to evaluate which types of achievement goals are more likely to evoke positive reactions in students. Overall, our results point to performance approach goals being especially beneficial to this end, whereas performance avoidance goals had adverse effects. Surprisingly, learning goals were not related to students' learning experiences in the expected direction, but were rather negatively associated with overall rating of teaching quality. When interpreting this finding, it needs to be considered that we only assessed teaching quality from the viewpoint of the students. Thus, it remains plausible that learning goals might evoke effective learning processes through challenging and new teaching techniques that might be perceived as tedious by the students but evoke deeper processing than techniques that they typically use. This would be in line with the frequently articulated criticism that student evaluations often reward entertaining and less challenging teaching techniques (see Stroebe, 2016). This reasoning could, in turn, also reflect that strong performance approach goals make teachers more prone to using teaching practices that are meant to elicit good feelings in students as well as the illusion of learning (rather than actual learning). Besides this notion, it is also highly plausible that learning goals are positively associated with experimentation during teaching (e.g., trying new teaching concepts or approaches). While such endeavors could provide important learning opportunities for the teachers (to master their teaching 
skills and methods), they might not work right away but rather lead to misguided experiments that could actually disrupt the learning processes of the students. Higher education teachers themselves may learn and benefit from such teaching experiments even if they fail, however, students could become largely frustrated by their experience in the respective course. As such, teachers' learning goals may be beneficial for teachers themselves (as reflected in more positive experiences when teaching, use of professional training, or lower rates of burnout; see Authors, 2020a), but not necessarily for the students' learning experiences. As such, following up on moderating or mediating factors related to actual teaching practices would constitute an important step forward to gain a clearer understanding about whether and how teachers' learning goals matter for students' learning. Doing so, we also consider it helpful to include further characteristics related to the teaching circumstance as moderators (e.g., teaching experience regarding a particular course, expertise on the respective topic).

Interestingly, our findings imply that students may react rather differently to teachers' relational goals. While boredom was negatively associated with this type of goal, students also felt that they learned less from teachers that were preoccupied with maintaining a good social climate in class. A reason for this could be that activities meant to facilitate such a climate compete with activities directed at enhancing learning when it comes to the distribution of time throughout the respective sessions.

\subsection{Limitations and Future Research}

While the inclusion of student ratings is an important strength of our work - and is a very appropriate method of assessing students' emotional experiences and their overall ratings - it also constitutes a limitation of our research design regarding the actual learning of the students. Although the teaching quality product factor of perceived learning might be cautiously interpreted as indication for learning gains, our results only allow us to conclude that higher education teachers' motivations have (prospective) relations with their students' learning experiences, while it is difficult to justify their motivations as being generally beneficial for objective learning. Thus, we recommend future research to consider additional measures for learning such as exams or standardized tests administered by researchers rather than the teachers, whose exam difficulty could be affected by their motivations as well. Further, we specifically focused on perceived product factors of teaching quality and emotions to reflect students' learning experiences. To better understand the mechanisms of how teacher motivations affect these factors, research would profit from including processrelated aspects of teaching quality as mediators (see Lazarides \& Buchholz, 2019; Schiefele, 2017). Furthermore, to more thoroughly elucidate differences in students' experiences and their relations to teachers' motivations, their own motivations may additionally be considered as moderating factors.

Further, both studies utilized prospective research designs within which we measured teachers' motivations before assessing students' experiences. Thus, our results speak more strongly to effects from teacher motivations on students' learning experiences rather than the other direction (students' experiences influencing teacher motivation). Nevertheless, our results are based on mere associations, meaning that we cannot rule out reciprocal relationships. Further, it might be the case that unmeasured third variables, such as time pressure or course composition, influence both teachers' motivations and students' learning motivations. This means that in terms of causally interpretable results, our research only provides a starting point for more intricate investigations (for example, using cross-lagged panel designs or experimental studies) to elucidate the causality behind the observed associations. These studies could also take longer time intervals into account (courses nested in years) that would allow for a better grasp on the impact of more generalized goals in the long term. We believe that there is still a long but promising way to go to achieve a comprehensive understanding of the impact of teachers' motivations for student learning.

This is also true regarding the generalizability of our results. With the present work, we specifically focused on teachers within higher education, as the research on the motivation of higher education professionals is an important new frontier within educational research (Daumiller, Stupnisky et al., 2020). Attesting the relevance of teaching motivations for students' learning experiences is an important step for this line of research. With that being said, the research on the relationship between teachers' motivations and student learning experiences within primary and secondary education is far from conclusive. We are convinced that our reasoning that it is important to consider the specificity of teachers' motivations when investigating the impact of teachers' motivations on students' learning experiences should also be transferable and inform research within other educational institutions. However, given the sys- 
temic differences between teaching at primary, secondary, and tertiary teaching institutions that we outlined in the introduction, we cannot be sure whether the observed relationships concerning the effects of the specific goals would be replicated in these different settings, which emphasizes the importance of expanding this line of research further. An important means to this end would also entail including relevant moderator variables that could affect the relevance of the motivations (e.g., frequency of interaction with students). Similarly, differences with regard to different countries and teaching contexts therein are possible (e.g., stronger relevance of relational goals in more collectivistic countries). Furthermore, the employment situation could impact the observed relationships (potentially differential relevance of different motivations for tenured or untenured employment). Unfortunately, we have no data on employment variables in our sample. Thus, we consider the incorporation of international research on teaching motivations key for a comprehensive understanding of these highly relevant processes (Watt, Richardson, \& Smith, 2017).

\section{Conclusion}

In our research, we sought to shed light on the largely neglected, yet paramount association between (university) teachers' motivations and students' learning experiences. The main take-away message is that specificity of motivation and, thus, the operationalization of motivation within research designs and questionnaires strongly matters for research on the effects of teacher motivations. While teachers' general self-efficacy beliefs were particularly relevant for students' perceived teaching quality and emotional experiences, achievement goals primarily mattered with regard to session-specific but not general goals. This might be due to a reduction of planning fallacies and a stronger consideration of the current teaching tasks and situational demands. We hope that our research not only reignites the overdue debate on the relevance of teachers' motivations for actual teaching outcomes but also illuminates how corresponding research questions in this important line of research should be addressed.

\section{Credit author statement}

Martin Daumiller: Conceptualization, Methodology, Software, Validation, Formal analysis, Investigation, Resources, Data curation, Writing - original draft, Writing - review \& editing, Visualization, Project administration.
Stefan Janke: Methodology, Writing - original draft, Writing - review \& editing, Project administration.

Julia Hein: Methodology, Investigation, Data curation, Writing - review \& editing.

Raven Rinas: Methodology, Investigation, Validation, Writing - review \& editing.

Oliver Dickhäuser: Methodology, Writing - review \& editing, Project administration, Funding acquisition.

Markus Dresel: Conceptualization, Methodology, Writing - review \& editing, Project administration, Funding acquisition.

\section{Declaration of competing interest}

We have no known conflicts of interest to disclose.

\section{References}

Abrami, P. C., d'Apollonia, S., \& Rosenfield, S. (2007). The dimensionality of student ratings of instruction. In R. P. Perry \& J. C. Smart (Eds.), The scholarship of teaching and learning in higher education (pp. 385-456). Dordrecht, Netherlands: Springer.

Austin, J., \& Vancouver, J. B. (1996). Goal constructs in psychology. Psychological Bulletin, 120, 338-375. doi:10.1037//0033-2909.120.3.338

Bandura, A. (1977). Self-efficacy. Psychological Review, 84, 191-215. doi:10.1037/0033-295X.84.2.191

Bandura, A. (1997). Self-efficacy. New York, NY: Freeman.

Bandura, A. (2001). Social cognitive theory. Annual Review of Psychology, 52, 1-26. doi:10.1111/1467-839X.00024

Beder, H. W., \& Darkenwald, G. G. (1982). Differences between teaching adults and pre-adults. Adult Education, 32, 142-155. doi:10.1177/074171368203200303

Bong, M. (2001). Role of self-efficacy and task-value in predicting college students' course performance and future enrollment intentions. Contemporary Educational Psychology, 26, 553-570. doi:10.1006/ceps.2000.1048

Bong, M. (2002). Stability and structure of self-efficacy, task-value, and achievement goals and consistency of their relations across specific and general academic contexts and across the school year. Retrieved from https://eric.ed.gov/?id=ED470665

Bong, M. (2004). Academic motivation in self-efficacy, task value, achievement goal orientations, and attributional beliefs. The Journal of Educational Research, 97, 297 298. doi:10.3200/JOER.97.6.287-298

Bürger, K., \& Schmitt, M. (2017). Students' multiple state goals as a function of appraisals, trait goals, and their interactions. Contemporary Educational Psychology, 51, 464-481. doi:10.1016/j.cedpsych.2017.09.006 
Butler, R. (2007). Teachers' achievement goal orientations and associations with teachers' help seeking. Journal of Educational Psychology, 99, 241-252. doi:10.1037/0022-0663.99.2.241

Butler, R., \& Shibaz, L. (2008). Achievement goals for teaching as predictors of students' perceptions of instructional practices and students' help seeking and cheating. Learning and Instruction, 18, 453-467. doi:10.1016/j.learninstruc.2008.06.004

Butler, R., \& Shibaz, L. (2014). Striving to connect and striving to learn. International Journal of Educational Research, 65, 41-53. doi:10.1016/j.ijer.2013.09.006

Caprara, G. V., Barbaranelli, C. Steca, P., \& Malone, P. (2006). Teachers' self-efficacy beliefs as determinants of job satisfaction and students' academic achievement. Journal of School Psychology, 44, 473- 490. doi:10.1016/j.jsp.2006.09.001

Cohen, J. (1988). Statistical power analysis for the behavioral sciences. Hillsdale, NJ: Lawrence Erlbaum.

Daumiller, M., Bieg, S., Dickhäuser, O., \& Dresel, M. (2020). Humor in university teaching: Role of teachers' achievement goals and self-efficacy for their use of content-related humor. Studies in Higher Education, 45, 2619-2633. doi:10.1080/03075079.2019.1623772

Daumiller, M., Dickhäuser, O., \& Dresel, M. (2019). University teachers' achievement goals for teaching. Journal of Educational Psychology, 111, 131-148. doi:10.1037/edu0000271

Daumiller, M., \& Dresel, M. (2020). Teaching and research. International Journal of Educational Research, 99. doi:10.1016/j.ijer.2019.08.002. Advanced online publication.

Daumiller, M., Fasching, M., Steuer, G., Dickhäuser, O., \& Dresel, M. (2021). From teachers' personal achievement goals to students' perceptions of classroom goal structures: Via student-oriented goals and specific instructional practices. doi:10.31234/osf.io/mvfth

Daumiller, M., Grassinger, R., Dickhäuser, O., \& Dresel, M. (2016). Structure and relationships of university instructors' achievement goals. Frontiers in Psychology, 7, 375. https://doi.org/10.3389/fpsyg.2016.00375

Daumiller, M., Grassinger, R., Engelschalk, T., \& Dresel, M. (2021). SEEQ-DE: Construction and validation of a German adaption of the instrument "Student Evaluation of Educational Quality" (Marsh) [SEEQ-DE: Konstruktion und Überprüfung einer deutschsprachigen Adaption des Instruments "Student Evaluation of Educational Quality" (Marsh)]. Diagnostica. doi:10.1026/0012-1924/ a000274. Advanced online publication.

Daumiller, M., Janke, S., Hein, J., Rinas, R., Dickhäuser, O., \& Dresel, M. (2021). Do teachers' achievement goals and self-efficacy beliefs matter for students' learning experiences? Evidence from two studies on perceived teaching quality and emotional experiences. Learning and Instruction. Advanced online publication. doi.org/10.1016/j.learninstruc.2021.101458

Daumiller, M., Rinas, R., Olden, D., \& Dresel, M. (2021).
Academics' motivations in professional training courses: Effects on learning engagement and learning gains. International Journal of Academic Development, 26(1), 7-23. doi.org/10.1080/ 1360144X.2020.1768396

Daumiller, M., Stupnisky, R., \& Janke, S. (2020). Motivation of higher education faculty. International Journal of Educational Research, 99, 101502. doi:10.1016/j. ijer.2019.101502

Dresel, M., Fasching, M. S., Steuer, G., Nitsche, S., \& Dickhäuser, O. (2013). Relations between teachers' goal orientations, their instructional practices and student motivation. Psychology, 4, 572-584. doi:10.4236/psych.2013.47083

Dweck, C. S. (1986). Motivational processes affecting learning. American Psychologist, 41, 1040-1048. doi:10.1037//0003-066x.41.10.1040

Eccles, J. S. (1983). Expectancies, values, and academic behaviors. In J. T. Spence (Ed.), Achievement and achievement motivation (pp. 75-146). San Francisco, CA: Freeman.

Eccles, J. S. (2009). Who am I and what am I going to do with my life. Educational Psychologist, 44, 78-89. doi:10.1080/00461520902832368

Elliot, A. J. (1999). Approach and avoidance motivation and achievement goals. Educational Psychology, 34, 169189. doi:10.1207/s15326985ep3403_3

Elliot, A. J. (2005). A conceptual history of the achievement goal construct. In A. J. Elliot \& C. S. Dweck (Eds.), Handbook of competence and motivation (pp. 52-72). New York, NY: Guilford.

Elliot, A. J., \& Hulleman, C. S. (2017). Achievement goals. In A. J. Elliot, C. S. Dweck, \& D. S. Yeager (Eds.), Handbook of competence and motivation ( $2^{\text {nd }}$ ed.; pp. 4360). New York, NY: Guilford.

Elliot, A. J., Murayama, K., \& Pekrun, R. (2011). A 3 x 2 achievement goal model. Journal of Educational Psychology, 103, 632-648. doi:10.1037/a0023952

Eyal, T., Sagristano, M. D., Trope, Y., Liberman, N., \& Chaiken, S. (2009). When values matter. Journal of Experimental Social Psychology, 45, 35-43. doi:10.1016/j.jesp.2008.07.023

Fong, C. J., Gilmore, J., Pinder-Grover, T., \& Hatcher, M. (2019). Examining the impact of four teaching development programmes for engineering teaching assistants. Journal of Further and Higher Education, 43, 363-380. doi:10.1080/0309877X.2017.1361517

Fong, C. J., Jendayi, B. D., \& Hatcher, M. (2019). Teaching self-efficacy of graduate student instructors. International Journal of Educational Research, 98. Advanced online publication. doi:10.1016/j.ijer.2019.08.018v

Frenzel, A. C., Goetz, T., Lüdtke, O., Pekrun, R., \& Sutton, R. E. (2009). Emotional transmission in the classroom. Journal of Educational Psychology, 101, 705-716. doi:10.1037/a0014695

Frenzel A. C., Goetz T., Stephens E. J., \& Jacob B. (2009). Antecedents and effects of teachers' emotional experiences. In P. Schutz \& M. Zembylas (Eds.) Advances in 
teacher emotion research (pp. 129-151). Boston, MA: Springer.

Fryer, J. W., \& Elliot, A. J. (2007). Stability and change in achievement goals. Journal of Educational Psychology, 99, 700-714. doi:10.1037/0022-0663.99.4.700

Goetz, T., Frenzel, A. C., Pekrun, R., Hall, N. C., \& Lüdtke, O. (2007). Between-and within-domain relations of students' academic emotions. Journal of Educational Psychology, 99, 715-733. doi:10.1037/0022$\underline{0663.99 .4 .715}$

Goetz, T., Sticca, F., Pekrun, R., Murayama, K., \& Elliot, A. J. (2016). Intraindividual relations between achievement goals and discrete achievement emotions. Learning and Instruction, 41, 115-125. doi:10.1016/j.learninstruc.2015.10.007

Gogol, K., Brunner, M., Goetz, T., Martin, R., Ugen, S., Keller, U., Fischbach, A., \& Preckel, F. (2014). "My questionnaire is too long!". Contemporary Educational Psychology, 39, 188-205. doi:10.1016/j.cedpsych.2014.04.002

Hein, J., Daumiller, M., Janke, S., Dresel, M., \& Dickhäuser, O. (2019). How learning time mediates the impact of university scholars' learning goals on professional learning in research and teaching. Learning and Individual Differences, 72, 15-25. doi:10.1016/j.lindif.2019.04.002

Holzberger, D., Philipp, A., \& Kunter, M. (2013). How teachers' self-efficacy is related to instructional quality. Journal of Educational Psychology, 105, 774-786. doi:10.1037/a0032198 doi:10.1016/j.lindif.2019.04.002

Hu, L. T., \& Bentler, P. M. (1999). Cutoff criteria for fit indexes in covariance structure analysis. Structural Equation Modeling, 6, 1-55. doi:10.1080/10705519909540118

Hulleman, C. S., ～Schrager, S. M., Bodmann, S. M., ～\& Harackiewicz, J. M. (2010). A meta-analytic review of achievement goal measures. Psychological Bulletin, 136, 422-449. doi:10.1037/a0018947

Ismayilova, K., \& Klassen, R. M. (2019). Research and teaching self-efficacy of university faculty. International Journal of Educational Research, 98. Advanced online publication. doi:10.1016/j.ijer.2019.08.012

Janke, S., \& Dickhäuser, O. (2018). A situated process model of vocational achievement goal striving within members of the academic staff at university. Motivation and Emotion, 42, 466-481. doi:10.1007/s11031-017-9657-z

Janke, S., \& Dickhäuser, O. (2019). A neglected tenet of achievement goal theory. Personality and Individual Differences, 142, 90-99. doi:10.1016/j.paid.2019.01.038

Kalyar, M.N., Ahmad, B., \& Kalyar, H. (2018). Does teacher motivation lead to student motivation. Voprosy obrazovaniya/Educational Studies Moscow, 3, 91-119. doi:10.17323/1814-9545-2018-3-91-119

Klassen, R., Bong, M., Usher, E., Chong, W., Har, H., V., Wong, I., \& Georgiou, T. (2009). Exploring the validity of a teachers' self-efficacy scale in five countries. Contemporary Educational Psychology, 34, 67-76. doi:10.1016/j.cedpsych.2008.08.001
Klassen, R. M., Tze, V. M., Betts, S. M., \& Gordon, K. A. (2011). Teacher efficacy research 1998-2009. Educational Psychology Review, 23, 2143.doi:10.1007/s10648-010-9141-8

Klassen, R. M., \& Tze, V. (2014). Teachers' self-efficacy, personality, and teaching effectiveness. Educational Research Review, 12, 59-76. doi:10.1016/j.edurev.2014.06.001

Koo, T. K., \& Li, M. Y. (2016). A guideline of selecting and reporting intraclass correlation coefficients for reliability research, Journal of Chiropractic Medicine, 15, 155163. doi:10.1016/j.jcm.2016.02.012

Lazarides, R., \& Buchholz, J. (2019). Student-perceived teaching quality. Learning and Instruction, 61, 45-59. doi:10.1016/j.learninstruc.2019.01.001

Lazarides, R., Buchholz, J., \& Rubach, C. (2018). Teacher enthusiasm and self-efficacy, student-perceived mastery goal orientation, and student motivation in mathematics classrooms. Teaching and Teacher Education, 69, 1-10. doi:10.1016/j.tate.2017.08.017

LeBreton, J. M., \& Senter, J. L. (2008). Answers to 20 questions about interrater reliability and interrater agreement. Organizational Research Methods, 11, 815-852. doi:10.1177/1094428106296642

Lee, M., \& Bong, M. (2016). In their own words. Journal of Educational Psychology, 108, 274-294. doi:10.1037/edu0000048

Little, T. D., Cunningham, W. A., \& Shahar, G. (2002). To parcel or not to parcel. Structural Equation Modeling, 9, 151-173. doi:10.1207/s15328007sem0902_1

Little, T. D., Rhemtulla, M., Gibson, K., \& Schoemann, A. M. (2013). Why the items versus parcels controversy needn't be one. Psychological Methods, 18, 285-300. doi:10.1037/a0033266

Marsh, H. W. (1982). SEEQ. British Journal of Educational Psychology, 52, 77-95. doi:10.1111/j.20448279.1982.tb02505.x

Marsh, H. W. (2007). Students' evaluations of university teaching. In R. P. Perry \& J. C. Smart (Eds.), The scholarship of teaching and learning in higher education (pp. 319-383). Dordrecht, Netherlands: Springer.

Marsh, H. W., Lüdtke, O., Trautwein, U., \& Morin, A. J. (2009). Classical latent profile analysis of academic selfconcept dimensions. Structural Equation Modeling, 16, 191-225. doi:10.1080/10705510902751010

Mascret, N., Elliot, A. J., \& Cury, F. (2015). The 3 x 2 achievement goal questionnaire for teachers. Educational Psychology, 37, 346-361. doi:10.1080/01443410.2015.1096324

Muthén, L., \& Muthén, B. (2017). Mplus (version 8.1) [Computer Software]. Los Angeles, CA: Muthén \& Muthén.

Nicholls, J. G. (1984). Achievement motivation. Psychological Review, 91, 328-346. doi:10.1037//0033295x.91.3.328 
Nie, Y., Lau, S., \& Liau, A. (2012). The teacher efficacy scale. The Asia-Pacific Education Researcher, 21(2), 414-421.

Nie, Y., Tan, G. H., Liau, A. K. Lau, S., Chua, B. L. (2013). The roles of teacher efficacy in instructional innovation. Educational Research for Policy and Practice, 12, 6777. doi:10.1007/s10671-012-9128-y

Nitsche, S., Dickhäuser, O., Fasching, M. S., \& Dresel, M. (2013). Teachers' professional goal orientations. Learning and Individual Differences, 23, 272-278. doi:10.1016/j.lindif.2012.07.017

Patterson, G. R., Reid, J. B., \& Dishion, T. J. (1992). Antisocial boys: Vol. 4. A social interactional approach. Eugene, OR: Castalia.

Peer, E., \& Babad,E. (2014). The Doctor Fox research (1973) rerevisited. Journal of Educational Psychology, 106, 36-45. doi:10.1037/a0033827

Pekrun, R., Goetz, T., Titz, W., \& Perry, R. P. (2002). Positive emotions in education. In E. Frydenberg (Ed.), Beyond coping (pp. 149-173). Oxford, England: Oxford University.

Pekrun, R., Goetz, T., Daniels, L. M., Stupnisky, R. H., \& Perry, R. P. (2010). Boredom in achievement settings. Journal of Educational Psychology, 102, 531-549. doi: $10.1037 / \mathrm{a} 0019243$

Perera, H. N., \& John, J. (2020). Teachers' self-efficacy beliefs for teaching math. Contemporary Educational Psychology, 61, 101842. doi:10.1016/j.cedpsych.2020.101842

Peugh, J. L., \& Enders, C. K. (2004). Missing data in educational research. Review of Educational Research, 74, 525-556. doi:10.3102/00346543074004525

Peugh, J. L., \& Heck, R. H. (2016). Conducting three-level longitudinal analyses. The Journal of Early Adolescence, 37, 7-58. doi:10.1177/0272431616642329

Praetorius, A.-K., Nitsche, S., Janke, S., Dickhäuser, O., Drexler, K., Fasching, M., \& Dresel, M. (2014). Here today, gone tomorrow. Contemporary Educational Psychology, 39, 379-387. doi:10.1016/j.cedpsych.2014.10.002

Retelsdorf, J., Butler, R., Streblow, L., \& Schiefele, U. (2010). Teachers' goal orientations for teaching. Learning and Instruction, 20, 30-46. doi:10.1016/j.learninstruc.2009.01.001

Rinas, R., Dresel, M., Hein, J., Janke, S., Dickhäuser, O., \& Daumiller, M. (2020). Exploring higher education teachers' achievement goals and discrete emotions. Frontiers in Psychology. Frontiers in Psychology, 11, 1-15. doi:10.3389/ fpsyg.2020.01484

Schiefele, U. (2017). Classroom management and masteryoriented instruction as mediators of the effects of teacher motivation on student motivation. Teaching and Teacher Education, 64, 115-126. doi:10.1016/j.tate.2017.02.004
Schiefele, U., \& Schaffner, E. (2015). Teacher interests, mastery goals, and self-efficacy as predictors of instructional practices and student motivation. Contemporary Educational Psychology, 42, 159-171. doi:10.1016/j.cedpsych.2015.06.005

Senko, C., \& Dawson, B. (2017). Performance-approach goal effects depend on how they are defined. Journal of Educational Psychology, 109, 574-598. doi:10.1037/edu0000160

Sparfeldt, J. R., Brunnemann, N., Wirthwein, L., Buch, S. R., Schult, J., \& Rost, D. H. (2015). General versus specific achievement goals. Learning and Individual Differences, 43, 170-177. doi:10.1016/j.lindif.2015.08.022

Steuer, G., \& Dresel, M. (2015). A constructive error climate as an element of effective learning environments. Psychological Test and Assessment Modeling, 57(2), 262275.

Stroebe, W. (2016). Why good teaching evaluations may reward bad teaching. Perspectives on Psychological Science, 11, 800-816. doi:10.1177/1745691616650284

Sutherland, K. S., Oswald, D. P. (2005). The relationship between teacher and student behavior in classrooms for students with emotional and behavioral disorders. Journal of Child and Family Studies, 14, 1-14. doi:10.1007/s10826-005-1106-z

Ting, K.-F. (2000). Cross-level effects of class characteristics on students' perceptions of teaching quality. Journal of Educational Psychology, 92, 818-825. doi:10.1037/0022-0663.92.4.818

Watt, H., Richardson, P., \& Smith, K. (2017). Global perspectives on teacher motivation. Cambridge, England: Cambridge University Press.

Woolfolk Hoy, A., Hoy, W. K., \& Davis, H. A. (2009). Teachers' self-efficacy beliefs. In K. R. Wenzel \& A. Wigfield (Eds.), Handbook of motivation at school (pp. 627-653). New York, NY: Routledge.

Yin, H., Han, J., \& Perron, B. (2020). Why are Chinese university teachers (not) confident in their competence to teach. International Journal of Educational Research, 100, 101529. doi:10.1016/j.ijer.2019.101529

Zee, M., \& Koomen, H. M. Y. (2016). Teacher self-efficacy and its effects on classroom processes, student academic adjustment, and teacher well-being. Review of Educational Research, 86, 981-1015. doi:10.3102/0034654315626801

Note. This is a pre-copyedited, author-produced PDF of an article in press. This paper is not the copy of record and may not exactly replicate the final, authoritative version of the article. The final article will be available, upon publication, via its DOI. 


\section{Footnotes}

${ }^{1}$ Furthermore, higher education teachers frequently also have other professional duties (such as research), also depending on the type of their institution (teaching-oriented vs. research-oriented universities). This marks them as a distinct population to primary and secondary school teachers. To reflect this, research works on this topic often also use terms such as "higher education faculty" to refer to this population. In the present work, we speak about higher education teachers as we exclusively focus on the teaching domain and their motivations for teaching.

${ }^{2}$ Daumiller, Dickhäuser et al. (2019) also considered task avoidance and learning avoidance goals. While these were empirically distinct from the other mastery-based goals, the authors did not find empirical evidence for their relevance. As we had no theoretical indications for the relevance of these goal types for teaching quality and students' emotions, we did not consider them in the present work (albeit we did assess them for exploratory reasons).

${ }^{3}$ A subsample of this study (teacher assessments at the first measurement point, also of those teachers without student assessments) was used to analyze the association between teachers' achievement goals with their own emotional experiences (Authors, 2020b).

${ }^{4}$ To keep the student evaluations as concise as possible (which was required for high participation rates and acceptance by the teachers), we used single items to measure the emotions (see Goetz et al., 2007, and Gogol et al., 2014, on the adequacy of such an approach).

${ }^{5}$ We do not report three-level analyses (students in courses in teachers), as most teachers participated with only one course. Nevertheless, we also ran these analyses. The results showed unacceptable SRMR values for the model fit on the course level, but regarding the association of teacher motivations with teaching quality and students' emotion, they were very similar.

${ }^{6} \mathrm{We}$ did not conduct four-level modeling (students in sessions in courses in teachers) as such models cannot yet be computed with Mplus. While four-level modelling would be possible with R, it does not readily allow incorporating latent variables in these analyses. Furthermore, as we were interested in shared students' assessments that we sought to predict by either session- or teacher- specific motivations, the incorporation of the student level in our analyses was not strictly necessary (no predictors of interest at the student level). Therefore, we derived and used the shared student assessments in prior analyses (justified by these measures being sufficiently reliable on the session level, as reflected in their ICC2s described above).

${ }^{7}$ Additionally, we also conducted random slope testing. Our results did not indicate significant slope variances, i.e., did not provide any indications that the effects of teacher motivations on student outcomes linearly differed across the five investigated sessions. 


\section{Appendix A. Supplementary data}

Table S1

Single Items Used in the Session-specific Questionnaire in Study 2

\begin{tabular}{ll}
\hline Assessed constructs & Item stem and items used \\
\hline Achievement goals & In today's session of this course, it is my goal... \\
Task approach & $\ldots$ to conduct my teaching tasks as well as possible. \\
Learning approach & $\ldots$ to further develop my own competences as much as possible. \\
Appearance approach & $\ldots$ that others notice how good my teaching is. \\
Appearance avoidance & $\ldots$ that others don't think my teaching is bad. \\
Relational & $\ldots$ to achieve a personal connection with students. \\
Work avoidance & $\ldots$ to have the least amount of work as possible. \\
Self-efficacy & What do you think: How well can you manage in today's session \\
& of this course ... \\
& .. to provide an alternative explanation or example when students \\
& .. to confused? \\
& $\ldots$ to keep a few problem students from ruining an entire lesson?
\end{tabular}

Note. The single items were chosen and slightly modified to the current context based on the most reliable and face-valid items from the Daumiller, Dickhäuser, et al. (2019) achievement goal scale and the Nie et al. (2010) self-efficacy scale. Achievement goals were to be answered on Likert-type scales ranging from 1 (do not agree at all) to 8 (agree completely), and self-efficacy beliefs on Likert-type scales ranging from 1 (absolutely not good) to 8 (exceedingly good). The item texts are a translation of the original German items and have not yet been validated in the English-speaking context. 
Table S2

Study 2: Results of Latent Multi-level Modeling the Associations Between Teachers' Motivations and Perceived Teaching Quality and Students' Emotions (Only Baseline Motivations for Teaching)

\begin{tabular}{|c|c|c|c|c|c|}
\hline \multirow{3}{*}{ Baseline motivations for teaching (Level 3) } & \multicolumn{5}{|c|}{ Student assessments: $\beta$ (S.E.) } \\
\hline & \multirow[t]{2}{*}{ Overall rating } & \multirow[t]{2}{*}{ Learning } & \multirow[t]{2}{*}{ Joy } & \multicolumn{2}{|c|}{ Boredom } \\
\hline & & & & & \\
\hline & $-.12(.14)$ & $-.45(.16)$ & $-.22(.16)$ & .12 & $(.16)$ \\
\hline Learning approach goals & $-.26(.12)$ & $-.09(.13)$ & $-.19(.12)$ & .24 & $(.13)$ \\
\hline Performance (appearance) approach goals & $.29(.24)$ & $.53(.24)$ & $.11(.29)$ & -.07 & $(.30)$ \\
\hline Performance (appearance) avoidance goals & $.29(.22)$ & $.09(.22)$ & $.40(.27)$ & -.39 & $(.28)$ \\
\hline Relational goals & $-.05(.12)$ & $-.06(.15)$ & $-.10(.15)$ & .10 & $(.14)$ \\
\hline Work avoidance goals & $-.14(.12)$ & $-.21(.12)$ & $.01(.13)$ & .01 & $(.15)$ \\
\hline Self-efficacy beliefs & $.37(.13)$ & $.39(.13)$ & $.41(.12)$ & -.44 & $(.13)$ \\
\hline \multicolumn{6}{|l|}{ Control variables } \\
\hline \multicolumn{6}{|l|}{ Session/student characteristics (Level 1) } \\
\hline Gender & $.04(.06)$ & $-.01(.04)$ & $.03(.04)$ & -.07 & $(.05)$ \\
\hline Prior interest & $.63(.04)$ & $.47(.04)$ & $.64(.05)$ & -.63 & $(.04)$ \\
\hline Participation reason & $.04(.07)$ & $-.02(.05)$ & $.04(.06)$ & -.02 & $(.06)$ \\
\hline Difficulty & $.04(.05)$ & $.41(.04)$ & $-.11(.05)$ & .03 & $(.05)$ \\
\hline \multicolumn{6}{|l|}{ Course characteristics (Level 2) } \\
\hline Lecture (yes or no) & $-.27(.09)$ & $-.26(.11)$ & $-.43(.08)$ & .48 & $(.08)$ \\
\hline \multicolumn{6}{|l|}{ Teacher characteristics (Level 3) } \\
\hline Age & $-.10(.11)$ & $-.28(.11)$ & $.09(.13)$ & .12 & $(.14)$ \\
\hline Gender & $-.03(.11)$ & $-.15(.11)$ & $.05(.13)$ & -.15 & $(.13)$ \\
\hline \multicolumn{6}{|l|}{ Explained variance } \\
\hline$R^{2}$ Level 1 & $.43(.05)$ & $.50(.04)$ & $.39(.05)$ & .40 & (.04) \\
\hline$R^{2}$ Level 2 & $.07(.05)$ & $.07(.05)$ & $.18(.07)$ & .23 & $(.08)$ \\
\hline$R^{2}$ Level 3 & $.35(.11)$ & $.49(.13)$ & .37 (.13) & .38 & (.13) \\
\hline
\end{tabular}

Note. $N=828$ assessed sessions (Level 1) within $N=182$ courses (Level 2) taught by $N=96$ teachers (Level 3). Reported are standardized coefficients with their standard errors in brackets. The dependent variables are the between part of student' session assessments (based on a total of $N=16,009$ student assessments). Statistically significant parameter estimates $(p<.05)$ are boldfaced. Cells highlighted with grey background indicate which parameters were statistically significant in the main analyses (that also included session-specific motivations for teaching; see Table 4 in the manuscript). All models yielded a satisfactory fit to the data: $\chi^{2} \leq 120.4, d f=94, \mathrm{CFI} \geq .97, \mathrm{TLI} \geq .95, \mathrm{SRMR}_{\text {Level1 }} \leq .01, \mathrm{SRMR}_{\mathrm{Level} 2} \leq .04$, $\mathrm{SRMR}_{\text {Level3 }} \leq .06, \mathrm{RMSEA} \leq .02$. 
Table S3

Study 2: Results of Latent Multi-level Modeling the Associations Between Teachers' Motivations and Perceived Teaching Quality and Students' Emotions (Only Session-specific Motivations for Teaching)

\begin{tabular}{|c|c|c|c|c|}
\hline & \multicolumn{4}{|c|}{ Student assessments: $\beta$ (S.E.) } \\
\hline & Overall rating & Learning & Joy & Boredom \\
\hline \multicolumn{5}{|c|}{ Current motivations for specific session (Level 1) } \\
\hline Task approach goals & $.02(.04)$ & $-.01(.04)$ & $.06(.04)$ & $-.07(.04)$ \\
\hline Learning approach goals & $-.16(.06)$ & $-.02(.05)$ & $-.06(.07)$ & $.17(.06)$ \\
\hline Performance (appearance) approach goals & $.16(.07)$ & $.15(.06)$ & $.10(.07)$ & $-.15(.06)$ \\
\hline Performance (appearance) avoidance goals & $-.07(.06)$ & $-.09(.04)$ & $-.13(.06)$ & $.12(.05)$ \\
\hline Relational goals & $.04(.06)$ & $-.10(.05)$ & $-.01(.05)$ & $-.13(.05)$ \\
\hline Work avoidance goals & $-.03(.05)$ & $.06(.05)$ & $-.03(.06)$ & $.03(.05)$ \\
\hline Self-efficacy beliefs & $.09(.05)$ & $.10(.05)$ & $.11(.06)$ & $-.07(.05)$ \\
\hline \multicolumn{5}{|l|}{ Control variables } \\
\hline \multicolumn{5}{|l|}{ Session/student characteristics (Level 1) } \\
\hline Gender & $.01(.06)$ & $-.02(.04)$ & $.02(.05)$ & $-.07(.05)$ \\
\hline Prior interest & $.61(.05)$ & $.46(.04)$ & $.64(.05)$ & $-.59(.04)$ \\
\hline Participation reason & $.01(.07)$ & $-.05(.04)$ & $.01(.05)$ & $-.02(.06)$ \\
\hline Difficulty & $.05(.05)$ & $.40(.04)$ & $-.12(.05)$ & $.01(.05)$ \\
\hline \multicolumn{5}{|l|}{ Course characteristics (Level 2) } \\
\hline Lecture (yes or no) & $-.27(.09)$ & $-.27(.11)$ & $-.42(.09)$ & $.48(.09)$ \\
\hline \multicolumn{5}{|l|}{ Teacher characteristics (Level 3) } \\
\hline Age & $-.13(.12)$ & $-.28(.12)$ & $-.01(.14)$ & $.19(.14)$ \\
\hline Gender & $.02(.12)$ & $-.14(.13)$ & $.02(.14)$ & $-.13(.15)$ \\
\hline \multicolumn{5}{|l|}{ Explained variance } \\
\hline$R^{2}$ Level 1 & $.46(.05)$ & $.52(.04)$ & $.42(.05)$ & $.44(.04)$ \\
\hline$R^{2}$ Level 2 & $.07(.05)$ & $.08(.06)$ & $.18(.08)$ & $.23(.09)$ \\
\hline$R^{2}$ Level 3 & $.02(.03)$ & $.07(.06)$ & $.01(.01)$ & $.07(.07)$ \\
\hline
\end{tabular}

Note. $N=828$ assessed sessions (Level 1) within $N=182$ courses (Level 2) taught by $N=96$ teachers (Level 3). Reported are standardized coefficients with their standard errors in brackets. The dependent variables are the between part of student' session assessments (based on a total of $N=16,009$ student assessments). Statistically significant parameter estimates $(p<.05)$ are boldfaced. Cells highlighted with grey background indicate which parameters were statistically significant in the main analyses (that also included general motivations for teaching; see Table 4 in the manuscript). All models were fully saturated and yielded a perfect fit to the data. 